This item was submitted to Loughborough's Research Repository by the author.

Items in Figshare are protected by copyright, with all rights reserved, unless otherwise indicated.

\title{
Surface treatments for inkjet printing onto a PTFE-based substrate for high frequency applications
}

PLEASE CITE THE PUBLISHED VERSION

http://dx.doi.org/10.1021/ie4006639

PUBLISHER

(C) American Chemical Society

VERSION

AM (Accepted Manuscript)

LICENCE

CC BY-NC-ND 4.0

REPOSITORY RECORD

Lim, Ying Ying, Yee M. Goh, and Changqing Liu. 2019. "Surface Treatments for Inkjet Printing onto a Ptfebased Substrate for High Frequency Applications”. figshare. https://hdl.handle.net/2134/13162. 
This item was submitted to Loughborough's Institutional Repository (https://dspace.lboro.ac.uk/) by the author and is made available under the following Creative Commons Licence conditions.

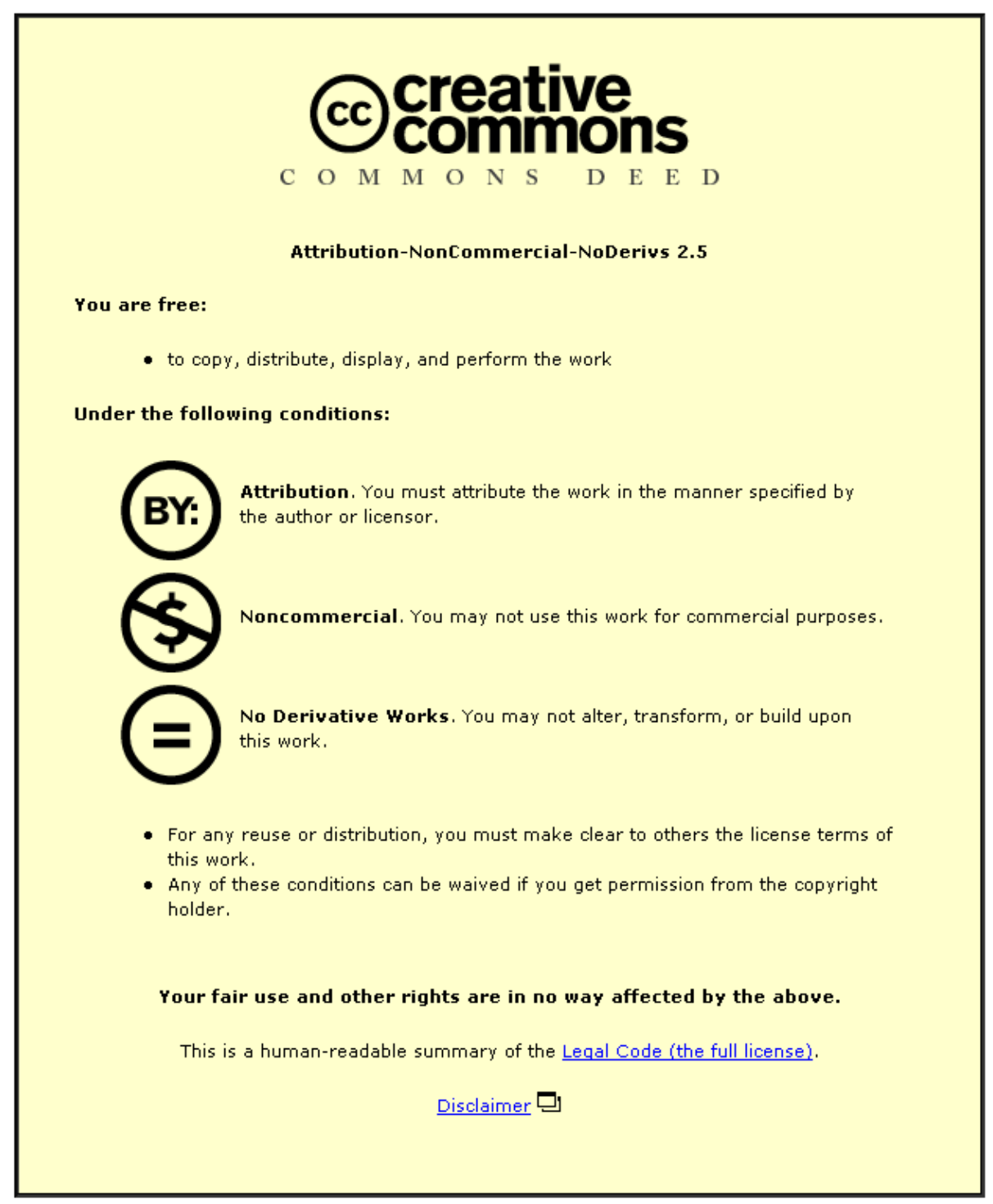

For the full text of this licence, please go to: http://creativecommons.org/licenses/by-nc-nd/2.5/ 


\section{Surface Treatments for Inkjet Printing onto a PTFE-}

\section{based Substrate for High Frequency Applications}

Ying Ying Lim*, Yee Mey Goh, Changqing Liu

Wolfson School of Mechanical \& Manufacturing Engineering, Loughborough University, Epinal

Way, Loughborough, Leicestershire, LE11 3TU, United Kingdom

\section{Corresponding Author}

*E-mail: y.y.lim@lboro.ac.uk, Phone: +44 (0) 1509227684 


\begin{abstract}
Inkjet printing onto laminates for use in high frequency applications (high frequency laminates) is challenging, due to the substrate surface roughness present after etching away the copper layer(s). This has a detrimental effect on interconnect losses as the frequency increases. In this paper, different surface treatments to reduce the surface roughness of a typical high frequency laminate (RO3006) are investigated. In particular, the importance of matching the substrate surface energy to the ink to achieve a smooth coated layer for the case of a UV cured insulator is demonstrated. This is achievable within the parameters of heating the platen, which is a more flexible approach compared to modifying the ink to improve the ink-substrate interaction. In printing onto the surface modified substrates, the substrate roughness was observed to affect the printed line width significantly. A surface roughness factor was introduced to take into account the phenomenon by modifying the original formula of Smith et al. ${ }^{1}$ Lastly, the authors show that the printed line widths are also influenced by the surface tension arising from charges present on the surface modified substrates.
\end{abstract}

KEYWORDS: inkjet printing, high frequency, PTFE, UV insulator, surface roughness 


\section{INTRODUCTION}

The emergence of wireless technology with consumer electronics has made wearable electronics increasingly pervasive in everyday life. Applications include health and physiological monitoring of the wearer (e.g. patients, athletes), through the enabling of wireless sensors. Another potential area is in military operations. For instance, body worn antennas operating on a wireless network would facilitate the communication between army personnel within patrol or other operational environments. Compared to traditional or mounted electronic devices, the key advantages include reduced weight, improved mobility and user comfort. Of late, there has also been a rising interest in millimeter-wave $(60-\mathrm{GHz})$ wireless body area networks (WBAN), due to concerns over security of data transfer using the current frequency bands. Additional requirements for wearable electronics are flexibility and the ability to withstand washing. ${ }^{2}$ From an electrical perspective, wearable electronics with low resistance are crucial for good performance, ${ }^{3}$ as this translates to low interconnect losses at higher frequencies.

Wireless sensors can be designed on a variety of substrates, ${ }^{4-6}$ according to the specific applications. In addition, previous work has identified several printing techniques which have the potential to be used in wearable electronics, such as the use of conductive threads and fabrics. ${ }^{6-9}$ The main drawback of using conductive threads is due to the minimum dimension achievable (1-1.5 mm). ${ }^{10}$ Furthermore, embroidered transmission lines were found to incur large losses which reduce the usable frequency range. Likewise, the plating thickness of conductive fabrics was found to be restricted to several hundred nanometers, ${ }^{11}$ in order to maintain textile properties. The ensuing implication of using conductive fabrics lies in the significant losses arising at higher frequencies due to the skin effect phenomenon. Other potential techniques for 
printing interconnects include screen printing, ${ }^{2,6}$ and inkjet printing. ${ }^{12}$ In particular, inkjet printing is an attractive method since it is an additive process which reduces the amount of waste generated, compared to the conventional printed circuit board (PCB) processes or screen printing. Furthermore, inkjet printing is appealing in terms of realizing low cost prototypes, compared to screen printing where stencils are required.

This paper seeks to investigate inkjet printing for high frequency wearable electronics applications. In this paper, a flexible laminate for use in high frequency applications (high frequency laminate) comprising of polytetrafluoroethylene (PTFE) composite material is considered (RO3006, Rogers Corporation). Furthermore its dielectric properties (Dielectric constant $=6.15 \pm 0.15$, loss tangent $=0.002)$ are well characterized up to $40 \mathrm{GHz} \cdot{ }^{13}$ RO3006 is used in this study as it has the potential to be a substrate platform for high frequency wearable electronics. ${ }^{14}$ This is due to its broadband dielectric properties, and to the fact that RO3006 is a relatively soft substrate compared to $\mathrm{FR}^{5}$, a glass-reinforced epoxy laminate commonly used to produce rigid PCBs. FR4 laminates are comprised of a woven mesh of glass fibre filled with organic fillers, and many variations of FR4 laminates are available depending on the type of filler used (epoxy). In contrast to FR4 laminates, the resulting substrate flexibility of RO3006 from its PTFE-based properties makes it viable for use in wearable devices.

A common challenge in inkjet printing onto RO3006 and other copper-cladded laminates lies in the substrate roughness after etching away the top metal layer, leaving copper dendrite imprints on the etched substrates. The degree of substrate roughness present on the substrates is a trade-off for good adhesion of the cladded copper to the laminate. In considering inkjet printing for high frequency wearable electronics, significant substrate roughness would increase the printed interconnect losses at higher frequencies, due to the skin depth effect. While authors have considered inkjet printing to realize antennas on paper at higher frequencies, ${ }^{15}$ the substrate 
surface roughness and its effect on interconnect losses have not been investigated. The rough surface profile of RO3006 (Figure 1) has necessitated the investigation of a suitable surface treatment technique to overcome the surface roughness of the substrate. The substrate topography of RO3006 resulted in the ink being absorbed into the pores, and the trace profile taking on the profile of the substrate. ${ }^{16}$

The effect of substrate roughness is particularly significant due to the slight metal thickness achievable for a single inkjet printed layer (typically $<1 \mu \mathrm{m}$ ). There is little literature addressing this issue in inkjet printing, as most researchers consider substrates with relatively smooth surfaces for the printing. ${ }^{1,17-19}$ Others have tried to alleviate the problem by interacting with the supplier to obtain substrates with a more favorable topography. ${ }^{12}$ This was achieved by purchasing substrates with minimal copper layer roughness, such that the copper cladding could be removed manually. ${ }^{12}$ This resulted in substrates with reduced surface roughness. Nevertheless, the supply of a customized substrate may increase the overall cost of manufacturing. Sridhar et al. also considered a plasma etching process to modify the surface of a high frequency substrate ${ }^{20}$ through a design of experiment (DoE) approach to vary the plasma etching parameters. However, the focus of their work in modifying the substrate surface characteristics was to improve the adhesion between the metal traces and the substrate. ${ }^{20}$ Consequently substrate surfaces which were sufficiently rough, with sufficiently high surface energies were preferable. ${ }^{20}$ In contrast, the aim of this paper is to achieve lower surface roughness for a typical high frequency laminate intended for the inkjet printing process, with the goal of improving the interconnect losses at higher frequencies. Specifically, this paper seeks to investigate suitable surface modification techniques to achieve the aim. 


\section{MATERIALS}

This section describes the materials used in the inkjet printing process, and for the various substrate modifications.

2.1. Ink Solution. Two types of nanoparticle-based conductive silver ink were selected to be used with a Dimatix inkjet printer. The first comprises of 30-35 wt \% silver (DGP 40LT-15C, Advanced Nano Products), with a surface tension of $35-38 \mathrm{mN} / \mathrm{m}$. The second ink is a composition of 20 wt \% silver (SunTronic EMD 5603, Sun Chemical), with a surface tension of $27-31 \mathrm{mN} / \mathrm{m}$. Both of the inks were selected based on their compatibility with the inkjet printer and the surface modified substrates.

2.2. Substrate Modifications. To reduce the substrate roughness, the surface treatments considered for RO3006 include: coating with a hydrophobic solution, spin-coating with a SU-8 dielectric and ink-jetting a UV curable insulator. The results obtained from these surface modified substrates were compared with that of untreated RO3006 substrates, in terms of the surface roughness and the printed line widths obtainable (Sections 4.3 and 4.4).

The hydrophobic coating considered was a 2 wt. \% fluorochemical acrylate polymer based in a hydrofluoroether solvent (EGC-1700, 3M Novec Electronic Coating). After application, the coating dries to a transparent film with a thickness of around $1 \mu \mathrm{m}$ (by dip-coating), with a surface energy in the range of $11-12 \mathrm{mN} / \mathrm{m} .{ }^{21}$ From Table 1 , the measured contact angle of water onto the coating is around $134^{\circ}$, and the surface energy of the hydrophobic coating calculated using two reference liquids is around $10 \mathrm{mN} / \mathrm{m}$, which agrees well with the value provided in the datasheet. $^{21}$ In this work, the coating was applied by brushing so as to minimize the contamination of the solution by the substrate. 
SU-8 (an epoxy based photo-resist, MicroChem Corp.) is a dielectric commonly used in silicon wafer processing to form passivation layers. In this case, SU-8 is applied to form a planarization layer onto RO3006, as illustrated in Figure 2. The application was done by spin-coating, with the process parameters based on conventional silicon wafer processing. Details of the process flow can be found in Supporting Information, Figure S1. Firstly, $6 \mathrm{ml}$ of the photo-resist was dispensed onto RO3006, and the coated substrate was soft baked at $95{ }^{\circ} \mathrm{C}$ for 1.5 minutes. Subsequently, the substrate was exposed on a mask aligner using an energy dosage of 250 $\mathrm{mJ} / \mathrm{cm}^{2}$ and post baked at two temperatures, namely $65{ }^{\circ} \mathrm{C}$ for 1.5 minutes, and $95{ }^{\circ} \mathrm{C}$ for 2 minutes. A final bake was performed on the coated substrate at $115^{\circ} \mathrm{C}$ for 5 minutes. Overall, two coats of SU-8 were applied on RO3006, as the first layer was found to be insufficient to coat over the substrate surface (Figure 3). This could be due to the presence of voids and craters in the surface arising from copper dendrite imprints (post-etching of the top copper layer). The contact angle of water on the SU-8 coating is provided in Table 1, along with its calculated surface energy.

Lastly, an UV curable insulator (Solsys Jettable Insulator EMD 6200, Sun Chemical) was applied to the surface of RO3006. The aim of using EMD 6200 is similar to the application of SU-8 (Figure 2), except that this dielectric is applied via inkjet printing. EMD 6200 is a research sample, with an ink viscosity of 7-9 mPas at $45^{\circ} \mathrm{C}$ and a surface tension of $23-27 \mathrm{mN} / \mathrm{m} .{ }^{22}$ At a temperature of $25^{\circ} \mathrm{C}$, the ink viscosity is $10-30 \mathrm{mPas}$ with a relative density of $1.02-1.1 .^{23}$ 


\section{METHODS}

This section details the parameters used in the inkjet printing process which includes the deposition of the UV curable insulator. In addition, the procedure for the contact angle measurements and surface morphology characterizations are described.

3.1. Contact Angle Measurements. Contact angle measurements involving different liquids were performed to ascertain the surface energy of the surface modified substrates as well as the ink-substrate interaction. The first involved measuring the contact angles of water (triply distilled water) onto the surface modified substrates. In addition, the contact angles of another reference liquid (diiodomethane) on the substrates were obtained, following which the surface energies of the surface modified substrates could be extracted using the Owen-Wendt-RableKaelble method, ${ }^{24}$ as shown in Table 1 . These contact angle measurements were performed using the Dataphysics OCA 20 instrument (DataPhysics Instruments GmbH, Germany). The droplet volumes used in the measurements were $2.0 \mu \mathrm{l}$ and a minimum of five measurements were obtained for each reference liquid on the surface modified substrates. Advancing contact angle measurements were also made using Dataphysics OCA 20. The second type of measurements was to ascertain the interaction of conductive silver inks with the surface modified substrates. This was performed using a Fibro Dat 1100 contact angle tester (Fibro System AB, Sweden), where a minimum of three static contact angle measurements were obtained for each surface modified substrate, recorded after $10 \mathrm{~s}$ following the droplet deposition. The droplet volumes used in the measurements were $4.0 \pm 0.5 \mu 1$. The measured contact angles of the silver inks with the surface modified substrates are shown in Table 2.

3.2. Inkjet Printing. A commercial drop-on-demand mode inkjet printer (DMP 2831, Fujifilm Dimatix Inc.) was used for the printing, with a $10 \mathrm{pl}$ print head. The cartridge comprised of 16 
nozzles. In the printing of conductive inks onto the surface modified substrates, a single jetting head with a $5 \mathrm{kHz}$ waveform was used. The inks were jetted out at temperatures of $25{ }^{\circ} \mathrm{C}$ (DGP 40LT-15C and EMD 5603). The dot spacing was kept at $20 \mu \mathrm{m}$ and the substrate was heated at $60{ }^{\circ} \mathrm{C}$ (platen temperature) during printing. The printed tracks were then thermally cured at 180 ${ }^{\circ} \mathrm{C}$ for 40 minutes.

3.3. UV curing. The UV lamp used for the curing of EMD 6200 is a $365 \mathrm{~nm}$ LED (PEL365, Printed Electronics Limited). Prior to the printing trials described in Table 3, the jetting waveform (at $5 \mathrm{kHz}$ ) for EMD 6200 was adjusted to minimize satellite drops. In addition, the drop velocity for EMD 6200 was tuned to $7 \mathrm{~m} / \mathrm{s}$ for the jetting process. The ink was jetted at a temperature of $45{ }^{\circ} \mathrm{C}$ as recommended in the datasheet. ${ }^{22}$ For the curing, a dosage (un-doped mercury) of $200-400 \mathrm{~mJ} / \mathrm{cm}^{2}$ was recommended for the processing of EMD $6200{ }^{22}$ The cure intensities obtained for levels 1, 2 and 3 using the UV lamp are $831 \mathrm{~mJ} / \mathrm{cm}^{2}, 1359 \mathrm{~mJ} / \mathrm{cm}^{2}$ and $2048 \mathrm{~mJ} / \mathrm{cm}^{2}$ respectively, following which a colorless coat was observed after curing. The time duration for curing a footprint of $4 \times 1 \mathrm{~cm}^{2}$ is around 14 minutes. To obtain a smooth coating, several printing trials were considered. These trials were performed to evaluate the effects of different curing intensities and platen temperatures. The respective process parameters are shown in Table 2.

3.4. Surface Morphology Characterization. The surface morphology of the modified RO3006 substrates were characterized using a non-contact measurement technique, based on the confocal point gauge principle (Talysurf CLI 2000, Talyor Hobson). This technique is considered to be more suitable for soft substrates, as RO3006 is PTFE-based. The measured area for each surface modified substrate was about $6 \times 4.5 \mathrm{~cm}$. The measurement range used was $300 \mu \mathrm{m}$, with a resolution of $10 \mathrm{~nm}$. Evaluation lengths of $3 \mathrm{~mm}$ were used for the characterization, with the sampling spacing set at $0.5 \mu \mathrm{m}$. During the post-processing, a Gaussian filter size cut off of 0.8 
mm was used, which is the recommended cut-off according to ISO $4288-1996{ }^{25}$ This cut off also represents the sampling length, following which an evaluation length of $3 \mathrm{~mm}$ yields a sample size of 4 . The surface roughness was measured at different areas of the substrate, and a total of 11 measurements were obtained and averaged. A summary of this characterization process is shown in Figure 4.

\section{RESULTS AND DISCUSSION}

4.1 Optimization of UV curing for EMD 6200. In Trials 1-3 from Table 3, the effects of the platen temperature and curing levels were investigated for a single layer coat. The ink-substrate interaction can be better understood through a consideration of the $Z$ number. The $Z$ number is the inverse of the Ohnesorge number $(\mathrm{Oh})$, and relates the viscous forces to the inertial and surface tension forces. This parameter is used as a dimensionless analysis of the effect of the ink properties on the drop formation, ${ }^{26-28}$ i.e. the printability of a fluid. A difference in the ink viscosity results in a change of the $Z$ number and the corresponding droplet volume. ${ }^{29}$ From equation (1):

$$
Z=O h^{-1}=\frac{\sqrt{\gamma \rho a}}{\eta}
$$

where $\gamma, \rho$ and $\eta$ are the surface tension, density and viscosity of EMD 6200, with the respective values provided in Section 2.2. $a$ represents the characteristic length, which is defined as the nozzle diameter in this case. For a $10 \mathrm{pl}$ cartridge, the nozzle diameter is calculated to be around $27 \mu \mathrm{m}$. At $25{ }^{\circ} \mathrm{C}$, which approximates the platen temperature without heating (room temperature), the calculated $\mathrm{Oh}$ is 0.75 for an average ink viscosity of $20 \mathrm{mPas}$ (viscosity range from $10-30 \mathrm{mPas}$ ). The reciprocal $Z=1 / O h$ yields a value of 1.33 , which is close to the lower bound for stable drop formation, where $1<Z<10 .{ }^{30}$ In contrast, the value of the $Z$-parameter 
increased to 3.33 at a higher temperature of $45^{\circ} \mathrm{C}$ with an ink viscosity of $8 \mathrm{mPas}$ (viscosity range from 7-9 mPas).

In printing with the platen temperature at room temperature $\left(18-20^{\circ} \mathrm{C}\right)$, the ink was found to de-wet upon contact with RO3006, due to a mismatch of the surface energies (Figure 5A). One possible way to reduce the de-wetting would be to lower the viscosity of the deposited ink, by heating the platen to aid in the degree of spreading. ${ }^{32}$ From the data in Section 2.2, EMD 6200 is observed to have a reduced viscosity of $7-9 \mathrm{mPas}$ at a temperature of $45{ }^{\circ} \mathrm{C}$, compared to a viscosity of $10-30 \mathrm{mPas}$ at $25{ }^{\circ} \mathrm{C}$. Consequently, the platen was heated to a maximum temperature of $60{ }^{\circ} \mathrm{C}$ to increase the mobility of the ink, and improve the ink-substrate interaction. From Figure 5B, it can be observed that the de-wetting phenomenon could be reduced with platen heating. This is consistent with the works of Gao et al. and Schiaffino et al., ${ }^{33-34}$ where it was suggested that a printed bead is likely to become unstable under conditions of a higher contact angle induced by a lower target temperature and/or contact line freezing induced by a lower target temperature as one of the key determinants. ${ }^{33}$ In their work, ${ }^{33}$ molten droplets were deposited onto a surface with varied temperatures. These solidify upon contact with the surface since the target temperature $\left(T_{f}\right)$ is lower than the jetting temperature $\left(T_{j}\right)$. This work bears some resemblance to those of Gao et al., ${ }^{33}$ in that the ink also undergoes solidification (albeit through a photochemical process), and the platen temperature is varied. In this case $\mathrm{T}_{j 1}<\mathrm{T}_{f}<\mathrm{T}_{j 2}$, where $\mathrm{T}_{j 1}$ represents room temperature $\left(18-20^{\circ} \mathrm{C}\right)$ and $\mathrm{T}_{j 2}$ represents a platen temperature of $60{ }^{\circ} \mathrm{C}$.

The de-wetting observed for EMD 6200 at room temperature could also be attributed to the surfactant package of the UV curable ink, which affects the ink wettability. From literature, Rebros et al. noted that the variation of a surfactant results in a significant change of the contact angle. ${ }^{31}$ From the ink formulation perspective, EMD 6200 , being an UV ink (100\% solids), has 
no solvents to be removed. As such, an increased spreading with a lower ink viscosity is aided by the relatively faster solidification through UV curing. This is in contrast to solvent-based silver inks which require a removal of the solvent contents by evaporation. As the solvent contents are reduced, the silver particles are less inclined to wet the substrate surface. On the other hand, the results for EMD 6200 suggest that the surfactant package of EMD 6200 promotes a wetting of the substrate surface, ${ }^{35}$ as the mobility of the ink particles increases due to a lower ink viscosity.

Following on the results in Trials 1 and 2, an increase of the curing levels in Trials 3 and 4 (Table 3) was observed to yield continuous coats. However the surface texture of the coated layers were observed to deteriorate with increased cure dosage, i.e the coated dielectric has a surface roughness relative to the level of UV energy used (Figure 5C, D). In addition, surface defects were visible throughout the coated layers in all 4 cases, which could be due to the low ink viscosity, following which any contamination on the surface would provide a locus for the de-wetting of the ink.

It was important to minimize the effects of surface defects, which could result in discontinuities of the printed traces. This led to the approach of building up layers of EMD 6200 by printing a second coat, so as to cover the surface defects. However, the challenge of obtaining a smooth coating in this approach lies in optimizing the control of the UV dose. Optimum conditions of UV curing were achieved in Trials 5-7.

In Trial 5, the effect of using an intermediate setting (cure level 2) was studied for a double layer coat, which was printed after the in-line curing for the first coat was completed. Compared to the first coat, the second coat revealed a visibly rougher surface, which could be due to the higher curing dosage at level 2. Similarly, when off-line curing for each of the layers was introduced in Trial 6, a visibly rougher surface was observed after the off-line curing of the 
second coat (Figure 6A, B). This could be due to an over-curing of the layers during UV exposure, resulting in an excess hardening of the coated layer. ${ }^{36}$ The use of a lower curing level (level 1) for both coats in Trial 7 was found to significantly improve the final coated surface (Figure 6C, D).

The average surface roughness $\left(R_{a}\right)$ for Trial 7 was $0.52 \mu \mathrm{m}$. The coated thickness has a slightly concave profile, and the thickness profile characterizations show that the surface of the printed dielectric has a non-uniform height, where the height at the edges is higher than the height in the center region. The authors suggest that this may be attributed to the coffee stain effect, ${ }^{37}$ where the fluid flows outwards to compensate for the evaporative effect for a pinned contact line. Further investigations would be required to better understand this phenomenon.

4.2. Platen Temperature and Cure Level. In an extension of the results obtained in Section 4.1, the effects of different platen temperature and cure levels on the coated thickness of EMD 6200 were investigated. The platen temperature varied from $30-60{ }^{\circ} \mathrm{C}$, in steps of $10{ }^{\circ} \mathrm{C}$, while the cure levels considered were level 1,1 and 1,2, for the first and second coat respectively. The rationale for considering a two stage curing is to under-cure the first layer (cure level 1), followed by a curing of both layers simultaneously. The results obtained are shown in Figure 7.

A few implications can be deduced from the results in Figure 7. Firstly, it was observed that a minimum temperature of $30{ }^{\circ} \mathrm{C}$ is sufficient to improve the ink mobility and minimize the dewetting phenomenon (Figure 8A, B). From Figure 7, the thicknesses of EMD 6200 are comparable when the platen temperature is set at $60{ }^{\circ} \mathrm{C}$, regardless of the cure levels. At lower platen temperatures $\left(40-50^{\circ} \mathrm{C}\right)$, an increase in the coated thicknesses was observed with a higher cure dosage (level 1,2). This phenomenon could be attributed to a reduced coffee stain effect, ${ }^{37}$ where a lower platen temperature results in a slower rate of evaporation of the volatiles in the ink 
prior to UV curing. Combined with a stronger cure level, the ink components would be cured at a faster rate.

Further results in Table 4 also suggest that the cured EMD 6200 is sensitive to the effects of heating, resulting in a thicker layer. The table shows the average thickness of EMD 6200 before and after thermal curing $\left(150^{\circ} \mathrm{C}, 30\right.$ minutes $)$. A significant reduction of the thickness by at least $20 \%$ was observed in the post curing stage. As the ink is $100 \%$ reactive, this suggests a possible shrinkage of the cured matrix. As the matrix is a polymer with some degree of porosity and a glass transition temperature, this decrease could be due to the expulsion of air as the polymer softens and compacts. In addition, RO3006, being an unreinforced ceramic-filled PTFE material, was found to warp after the thermal cure. This was because the substrate was etched to remove the top copper layer and was exposed to elevated temperatures. The warpage of RO3006 went beyond the upper limit of $106 \mu \mathrm{m}$ (fine range) when measured with a contact stylus (Talysurf CLI 2000, Taylor Hobson). One implication of this substrate warpage would be in the fabrication of multi-layer circuits based on inkjet printing, where misalignment issues may arise in attempting to align one metal layer with another.

The surface roughness values for cure levels 1,1 and 1,2 are comparable, with slightly lower values obtained for reduced cure levels. The values of $R_{a}$ range from $0.47-0.52 \mu \mathrm{m}$ and $0.52-0.67$ $\mu \mathrm{m}$ for cure levels 1,1 and 1,2 respectively.

4.3. Results of Surface Morphology Characterization. Following the characterization procedure in Section 3.4, the results obtained are presented in the form of an error bar plot (Figure 9). The values are also listed in the Supporting Information, Table S1. From Figure 9, it can be observed that the hydrophobic-coated RO3006 has a mean value comparable to the untreated substrate. This suggests that the application of the hydrophobic coating via brushing was insufficient to cover surface roughness. One possible factor could be that the hydrophobic 
layer formed via brushing, was non-uniform in certain sections of the substrate. Furthermore, the solids content in the hydrophobic solution was only around $2 \%$, which could have been deposited in the pores of the substrate during the coating process. As such, obtaining a thicker coat would require either several times of dip-coating (where thicknesses of around $1 \mu \mathrm{m}$ can be obtained through dip-coating), ${ }^{21}$ or using a hydrophobic coating with a higher solids content. Due to concerns of contaminating the sample solution (limited volume) by the substrate, dipcoating was not used to apply the coating onto RO3006, and it is planned to include the suggested applications to obtain a thicker hydrophobic coating in future.

The application of SU-8 was most effective in alleviating the substrate surface roughness. The mean value for the SU-8 coat is lower by at least $70 \%$ for $R_{a}$, compared to the untreated RO3006. However, printing trials of a simple trace revealed significant de-wetting of the ANP ink onto the SU-8 coated substrate, due to an incompatibility of the ink with the substrate. For this reason, a corona treatment was applied onto the SU-8 coated substrate ( $15 \mathrm{kV}$ at a power of $15 \mathrm{~W})$ to modify its surface tension. The measured contact angle after corona treatment was $20^{\circ}$, which indicates an increase in the surface energy of the SU-8 coated substrate, with reference to Young's equation. ${ }^{38}$ After printing, bulges were observed for the traces (Figure 10A). It is believed that the bulging of the metal traces on SU-8 could be due to the small drop pitch (20 $\mu \mathrm{m})$ used during printing, in which the drops are being placed too close together. ${ }^{39}$ In addition, the change in the surface tension arising from the corona treatment of the substrate (lower contact angle) could have possibly resulted in the ink spreading. The trace outlines were observed to follow the texture (swirls) on the SU-8 coating (Figure 10B), which suggests an uneven coat. The swirls could arise from the SU-8 surface drying much faster compared to the inner regions during processing. In addition, substrate bowing may also be a contributing factor to the uneven SU-8 coat, since the PTFE-based R03006 is a soft material which was slightly 
warped in a guillotine cut during sample preparation. An optimization of corona treatment parameters would be essential for obtaining the targeted line widths. Prior to that, the spincoating parameters would need to be optimized for the particular substrate, to minimize the swirls on the coated SU-8 layer. Consequently, improved trace definition could then be obtained with inkjet printing.

4.4 Effect of Substrate Roughness on Printed Line Widths. Wenzel ${ }^{40}$ considered the effect of surface roughness on the contact angle through a roughness factor. Smith et al. ${ }^{1}$ printed conductive tracks onto several substrates, and introduced a simple empirical model relating the printed width to the equilibrium contact angle. Nevertheless, data on the substrate surface roughness were not available, and it was unclear what their effect on the printed line widths were. As a result, the good agreement obtained between the calculated and the printed widths ${ }^{1}$ could be due to the negligible surface roughness of the substrates considered (e.g. glass) for inkjet printing. The substrate roughness was found to influence the printed line widths significantly in this work, and a surface roughness factor was introduced to account for the increased line widths.

With reference to Figure 11, the surface roughness increases the actual width of a printed trace. In this case, the authors consider:

$$
w_{1}=w * k=(2 r \sin \theta) k
$$

where $k$ represents the surface roughness factor, and $w$ represents the width of a trace on a smooth surface (of negligible surface roughness). Substituting $w_{1}$ into the equation by Smith et al., ${ }^{1}$ we obtain a modified expression for the trace width as shown in equation (3), taking into account the surface roughness: 


$$
w_{1}^{2}=\frac{\frac{\pi d^{3}}{6 \Delta x}}{\frac{\theta}{4 k(\sin \theta)^{2}}-\frac{\cos \theta}{4 k \sin \theta}}
$$

The final expression for the actual trace width can be expressed in equation (4) as:

$$
\mathrm{w}_{1}=\sqrt{\frac{\left(2 \pi d^{3} k\right)}{3 \Delta x\left[\frac{\theta}{\sin ^{2} \theta}-\frac{\cos \theta}{\sin \theta}\right]}}
$$

where $\theta$ (in radians) is the contact angle formed by the droplet on the substrate, $\Delta x$ is the dot spacing and $d$ is the droplet diameter. This equation assumes that the surfaces are of low or negligible porosity, as porous surfaces could result in a penetration of the silver nanoparticles into the surface. ${ }^{41}$ The effect of porosity is typically considered in literature for coated substrates such as paper, ${ }^{41-44}$ where the pore size distribution and network structure of the coating layer would affect the speed of ink penetration into the pores. ${ }^{42}$ Much of the literature involving coated layers considered dye-based inks, ${ }^{42-44}$ though Ohlund et al. ${ }^{41}$ considered the conductivity obtained from printing silver based inks onto coated papers. ${ }^{41}$

For substrates without coatings, porosity could be considered in terms of the water absorption into the substrate according to the IPC-TM-650-2.6.2 test method (i.e. material immersed in distilled water at $23{ }^{\circ} \mathrm{C}$ for 24 hours). ${ }^{45}$ Ohlund et al. ${ }^{41}$ considered a polyimide film (Kapton HN, Dupont) as a nonporous reference substrate in their work, which had a water absorption of 2.8\%. ${ }^{46}$ Apart from Kapton, Smith et al. ${ }^{1}$ also considered Teflon, sodalime glass, carbon fiber and glass fiber reinforced epoxy compositions for their equation which relates the trace width to the contact angle. The corresponding water absorption of these materials were in the range of $0.01-0.5 \%{ }^{47-48}$ In this work, the RO3006 substrate has a water absorption of $<0.1 \% .{ }^{13}$ From Figures 13-14, the planarization layers (SU-8 coat and EMD 6200 coat) considered in this work 
were observed to be porous. For the purpose of simplification, these coated surfaces would be excluded from consideration using equation (4).

Test lines of $1 \mathrm{~cm}$ length were printed onto the surface modified substrates, as shown in Figure 12. The printed line widths were subsequently measured using an optical microscope (Smartscope Flash 200, Optical Gauging Products), and the best fit values were obtained and averaged. These measured values were compared with the calculated values from the empirical formula introduced by Smith et al. ${ }^{1}$ The values are shown in Table 5.

From equation (4), it can be deduced that finer line widths can be obtained by printing onto a high contact angle substrate. This is verified by the lower line width variation observed on the hydrophobic coated RO3006 (Table 4) compared to the other surfaces. For the untreated and hydrophobic coated RO3006 substrate, a value of 1.2 was used for $k$ to predict the line widths as shown in Table 5. This value of $k$ is for a range of $\mathrm{R}_{\mathrm{a}} \leq 1 \mu \mathrm{m}$. To validate this range, a third sample was obtained by applying an abrasive sheet (Grit range P1200, Norton T489) to the RO3006 substrate to roughen the surface, where a measured $R_{a}$ of $0.8 \mu \mathrm{m}$ was obtained. Test lines of $1 \mathrm{~cm}$ length were then printed and equation (4) used to predict the line width, for which the results are shown in Table 5. A variation of within $10 \%$ was observed between the predicted and measured line widths.

The relation between the correction factor and the static contact angle $(\theta)$ is further investigated as shown in equation (5), where $k$ can be represented as a function of $\theta$ and $w_{1}$ :

$$
k=f\left[\left(\frac{\theta}{(\sin \theta)^{2}}-\frac{\cos \theta}{\sin \theta}\right) w_{1}^{2}\right]
$$

From equation (5), it can be deduced that $k$ would decrease as $\theta$ increases, since a higher contact angle results in a reduced line width. As $w_{1}$ is in the range of $\mu \mathrm{m}$, this implies that $k$ would be more significantly affected by changes in $w$ (i.e. the $w_{1}{ }^{2}$ parameter) compared to variations in $\theta$ 
which are in units of radians. From equation (5), a closer match between the measured and predicted line width by Smith et al. ${ }^{1}$ can be observed as $\theta$ approaches $90^{\circ}$ (i.e. $k \rightarrow 1$ ). This is also graphically represented in Figure 15 which shows the correlation of the measured static contact angle against the predicted line widths, with and without the factor $k$.

4.5 Effect of Printing Silver Inks onto EMD 6200. In printing the test line onto doublecoated EMD 6200 using EMD 5603, partial de-wetting was found to occur at a platen temperature of $60{ }^{\circ} \mathrm{C}$ (Figure 12D). Bulges were observed for the printed trace, which occurred at regular intervals. ${ }^{17,49}$ The width of the connecting ridge between adjacent bulges was reduced from an initial $60 \mu \mathrm{m}$ (printed width) to $10 \mu \mathrm{m}$. In some line sections, breaks in the connecting ridges were observed (Figure 12D). This line thinning down to $10 \mu \mathrm{m}$ could be attributed to the pumping of the ink from the ridge to the bulge arising from a pressure difference. ${ }^{17}$ In addition, it could be due to the fine dimensions being considered for printing. In particular, the width of the ridge was observed to be smaller than the diameter of single printed drops on the substrate (as shown in Figure 16), which had diameters of around $30 \mu \mathrm{m}$. Compared to the calculated drop diameter of $26.7 \mu \mathrm{m}$ from a $10 \mathrm{pl}$ print head, this suggests that negligible spreading (i.e. dewetting) of the conductive ink had occurred. This was also verified using contact angle calculations in equation (6). While the measured contact angle of the ink-substrate was $45 \pm 5^{\circ}$ (at room temperature), the printed drops were observed at a platen temperature of $60{ }^{\circ} \mathrm{C}$. The corresponding contact angle for the printed drops calculated using equation (6) was around 102 ${ }^{\mathrm{o}} \mathrm{C},{ }^{17}$ where:

$$
\frac{b_{0}}{D}=\left(\frac{4 \sin ^{3} \theta}{(1-\cos \theta)^{2}(2+\cos \theta)}\right)^{1 / 3}
$$


In equation (6), $b_{0}$ is the width of a drop on the substrate, $D$ is the diameter of the droplet and $\theta$ is the contact angle. This significant increase in contact angle suggests a minimal spreading of the printed droplets.

As observed in Figure 17, an initial trace outline was observed after printing, which subsequently shrunk to that defined by the metal trace. This de-wetting phenomenon was also investigated using dynamic contact angle measurements. The static and advancing contact angles of acetone onto the double-coated EMD 6200 were measured, as the surface tension of acetone was found to be close to that of EMD $5603\left(25.2 \mathrm{mN} / \mathrm{m}\right.$ at $\left.20{ }^{\circ} \mathrm{C}\right)$. The measured results are shown in Table 6. From Table 6, the static contact angle $(\theta)$ was found to be close to the advancing contact angle $\left(\theta_{\mathrm{a}}\right)$, which is near the boundary condition for an unstable line (i.e. $\theta>$ $\left.\theta_{\mathrm{a}}\right){ }^{17,50}$ Another factor contributing to the line instability could be due to the movement of the contact line during the drying process, as the substrate is heated by the platen below with a temperature of $60{ }^{\circ} \mathrm{C} .{ }^{18,33-34}$ Unlike the UV-curable ink (EMD 6200), as EMD 5603 becomes more mobile, the surfactant package of the ink results in the silver nanoparticles being less likely to wet the surface as the solvent is removed. ${ }^{35}$

In addition, the charging of the surface during the UV exposure could be another possible factor for the de-wetting observed. The charging of the dielectric layer could vary according to the curing system used, where the extent of curing (e.g. curing depth) may differ compared to another system. Furthermore, there is a possibility of a degradation of the LED used in the UV curing, resulting in an uncertainty of the curing dosage and thus the extent of the dielectric cured during printing.

One possible way of alleviating the de-wetting phenomenon could be to use a conductive ink with a higher concentration or viscosity. ${ }^{51}$ In this case, the DGP 40LT-15C ink (30-35\% solid content) was used for printing onto EMD 6200. While no de-wetting was observed, the metal 
trace formed was found to deposit beneath the UV dielectric, and no resistance values could be measured. This could possibly arise from an incompatibility of the solvents in the silver ink with EMD 6200, in which the solvent could be partially dissolving the film and providing a path to the base of the insulator. Further investigations would be required to understand this phenomenon.

\section{CONCLUSIONS}

The important results of this paper are summarized as follows:

- Methods for reducing the surface roughness on a high frequency laminate after copper etching have been described, by considering various surface modification techniques hydrophobic coating, SU-8 coating and UV curable jettable insulator. In particular, the jetting parameters of the UV curable insulator were optimized to obtain a smooth layer over the substrate roughness, with an average surface roughness of $0.44 \mu \mathrm{m}$ obtained.

- The importance of matching the surface energy of the substrate to the ink is highlighted by the use of the UV cured insulator. While this can be achieved with ink modification, the authors have shown that this is possible within the parameters of heating the platen, which is a more flexible approach.

- In another aspect of this work, the substrate roughness was also observed to affect the printed line width significantly, and a surface roughness factor was introduced in the equation of Smith et al. ${ }^{1}$ to take into account this phenomenon. The surface roughness factor is valid for $R_{a} \leq 1 \mu \mathrm{m}$.

- Lastly, the authors have shown that the contact angle and the substrate surface roughness are not sufficient conditions to determine the printed trace width. This is because the surface tension arising from the charges on the surface modified substrate is another 
possible factor which needs to be taken into account, as observed for the corona treated SU-8 coat and the UV cured insulator on RO3006.

\section{ACKNOWLEDGMENTS}

The authors are grateful to Dr Steve Jones and Dr Neil Chilton for allowing them access to the inkjet printers at Printed Electronics Limited and offering their expertise in printed electronics. In addition, they would like to thank Rogers Corporation for the provision of the RO3006 laminates, as well as Steve Henly from Acota for the provision of the hydrophobic coating. They would like to express their gratitude to Mr Peter Walsh from Sun Chemical for the provision of samples of EMD 6200, and to Mr Mike Pickrell from Sun Chemical for his invaluable technical support rendered in the evaluation of EMD 6200. Lastly, they would like to acknowledge the Centre for Process Innovation Limited and Dr Gary Ternent from the University of Glasgow for their help in the process evaluation of the SU-8 samples.

\section{Supporting Information Available}

Detailed process flow for the application of SU-8 onto RO3006 substrate, and the mean values of $R_{a}$ with the upper and lower error limits (surface morphology characterization) are provided. This material is available free of charge via the Internet at http://pubs.acs.org. 


\section{REFERENCES}

(1) Smith, P.J.; Shin, D.-Y.; Stringer, J.E.; Derby, B. Direct Ink-jet Printing and Low Temperature Conversion of Conductive Sliver Patterns. J. Mater. Sci. 2006, 41, 4153.

(2) Karaguzel, B.; Merritt, C.R.; Kang, T.; Wilson, J.M.; Nagle, H.T.; Grant,E.; Pourdeyhimi, B. Flexible, Durable Printed Electrical Circuits. J. Text. Inst. 2009, 100, 1.

(3) Chung, S.; Lee, J.; Song, H.; Kim, S.; Jeong, J.; Hong, Y. Inkjet-printed Stretchable Sliver Electrode on Wave Structured Elastomeric Substrate. Appl. Phys. Lett. 2011, 98, 1.

(4) Yang, L.; Rida, A.; Vyas, R.; Tentzeris, M.M. RFID Tag and RF Structures on a Paper Substrate Using Inkjet-Printing Technology. IEEE Trans. Microwave Theory Tech. 2007, 55, 2894.

(5) Alomainy, A.; Hao, Y.; Pasveer, F. Numerical and Experimental Evaluation of a Compact Sensor Antenna for Healthcare Devices. IEEE Trans. Biomed. Circuits Syst. 2007, 1, 242.

(6) Merilampi, S.; Ruuskanen, P.; Bjorninen, T.; Ukkonen, L.; Sydanheimo, L. Printed Passive UHF RFID Tags as Wearable Strain Sensors. In Proceedings of International Symposium on Applied Science in Biomedical and Communication Technology (ISABEL), Rome, Italy, 2010, pp.1-5.

(7) Hay, G.I.; Evans, Peter S.A.; Harrison, D. J.; Southee, D.; Simpson, G.; Harrey, Paul M. Characterization of Lithographically Printed Resistive Strain Gauges. IEEE Sens. J. 2005, 5, 864.

(8) Ando, B. Inkjet-printed Sensors: A Useful Approach for Low Cost, Rapid Prototyping. IEEE Instrum. Meas. Mag. 2011, 14, 36. 
(9) Siden, J.; Nilsson, H-E. Line Width Limitation of Flexographic-Screen-and Inkjet printed RFID Antennas. In Proceedings of IEEE Antennas Propag. Soc. Int. Symp. (APSURI), Honolulu, Hawaii, 2007, pp. 1745-1748.

(10) Maleszka, T. Wroclaw University of Technology, Wroclaw, Poland. Personal communication, 2011.

(11) Locher, I.; Klemm, M.; Kirstein, T.; Troster, G. Design and Characterization of Purely Textile Patch Antennas. IEEE Trans. Adv. Packag. 2006, 29, 777.

(12) Sridhar, A.; Reiding, J.; Adelaar, H.; Achterhoek, F., van Dijk, D.J.; Akkerman, R. Inkjetprinting- and Electroless-plating-based Fabrication of RF Circuit Structures on High-frequency Substrates. J. Micromech. Microeng. 2009, 19, 1.

(13) RO3000 ${ }^{\circledR}$ Series Circuit Materials; Rogers Corporation: Connecticut, Nov 2011 http://www.rogerscorp.com/acm/products/15/RO3000-and-RO3200-series-High-FrequencyLaminates-PTFE-Ceramic.aspx (accessed Mar 1, 2012).

(14) Vasylchenko, A.; Farserotu, J.F.; Brebels, S.; De Raedt, W.; Fernández-Bolaños, M.; Ionescu, A.M.; Vandenbosch, G.A.E. Scalable Conformal Array for Multi-Gigabit Body Centric Wireless Communication. In Proceedings 5th International Symposium on Medical Information \& Communication Technology (ISMICT 2011), Montreux, Switzerland, 2011, pp. 74-78.

(15) Yang, L.; Rids, A.; Vyas, R.; Tentzeris, M.M. RFID Tag and RF Structures on a Paper Substrate Using Inkjet-Printing Technology. IEEE Trans. Microwave Theory Tech. 2007, 55, 2894. 
(16) Lim, Y.Y.; Goh, Y.M.; Liu, C.-Q. RF Performance of Inkjet and Stencil Printed Traces for Flexible Electronics Applications. In Proceedings of the 14th Electronics Packaging Technology Conference (EPTC2012), Singapore, 2012; pp 572-578.

(17) Duineveld, P.C. The Stability of Ink-jet Printed Lines of Liquid with Zero Receding Contact Angle on a Homogeneous Substrate. J. Fluid Mech. 2003, 477, 175.

(18) Shin, D.-Y. Fabrication of an Inkjet-printed Seed Pattern with Sliver Nanoparticulate Ink on a Textured Silicon Solar Cell Wafer. J. Micromech. Microeng. 2010, 20, 125003.

(19) Li, Y.; Torah, R.; Beeby, S.; Tudor, J. An All-inkjet Printed Flexible Capacitor for Wearable Applications. In Proceedings of Symposium on Design, Test, Integration and Packaging of MEMS/MOEMS (DTIP), Cannes, France, 2012; pp. 192-195.

(20) Sridhar, A.; Perik, M. A.; Reiding, J., van Dijk, D.J.; Akkerman, R. Fabrication of RF Circuit Structures on a PCB Material using Inkjet Printing - Electroless Plating and the Substrate Preparation for the Same. Trans. Jpn. Inst. Electron. Packag. 2009, 2, 116.

(21) $3 \mathrm{M}$ Novec ${ }^{\mathrm{TM}}$ Electronic Coating EGC-1700, 3M: Minnesota, Sep 2001 http://solutions.3m.com/wps/portal/3M/en_US/3MNovec/Home/ProductCatalog (accessed Mar 1, 2012).

(22) SunTronic Solsys Jettable Insulator EMD6200, Sun Chemical, Feb 2011.

(23) Clear UV Dielectric Ink EMD 6200; SDS; Sun Chemical: Bath, Somerset, Jun 7, 2012.

(24) Owens, D.K.; Wendt, R.C. Estimation of the Surface Free Energy of Polymers. J. Appl. Polym. Sci. 1969, 13, 1741. 
(25) International Organization for Standardization. ISO 4288:1996 Geometrical Product Specifications (GPS) - Surface texture: Profile method - Rules and procedures for the assessment of surface texture, 2nd ed.; Geneva, 2013.

(26) Derby, B. Inkjet Printing Ceramics: From Drops to Solid. J. Eur. Ceram. Soc. 2011, 31, 2543.

(27) Tekin, E.; Smith, P. J.; Schubert, U.S. Inkjet Printing as a Deposition and Patterning Tool for Polymers and Inorganic Particles. Soft Matter. 2008, 4, 703.

(28) Fromm, J.E. Numerical Calculation of the Fluid Dynamics of Drop-on-Demand Jets. IBM J. Res. Dev. 1984, 28, 322.

(29) Perelaer, J.; Smith, P.J.; Wijnen, M.M.P.; Van den bosch, E.; Eckardt, R., Ketelaars, P.H.J.M.; Schubert, U. S. Droplet Tailoring Using Evaporative Inkjet Printing. Macromol. Chem. Phys. 2009, 210, 387.

(30) Reis, N.; Ainsley, C.; Derby, B. Ink-jet Delivery of Particle Suspensions by Piezoelectric Droplet Ejectors. J. Appl. Phys. 2005, 97, 094903.

(31) Rebros, M.; Fleming, P.D.; Joyce, M.K. UV-inks, Substrates and Wetting, In Proceedings of TAPPI Coating and Graphics Arts Conference, Atlanta, 2006; pp. 1-7.

(32) Perealer, J.; Smith, P.J.; van den Bosch, E.; van Grootel, S.S.C.; Ketelaars, P.H.J.M.; Schubert, U.S. The Spreading of Inkjet-Printed Droplets with Varying Polymer Molar Mass on a Dry Solid Substrate. Macromol. Chem. Phys. 2009, 210, 495.

(33) Gao, F.; Sonin, A.A. Precise Deposition of Molten Microdrops: The Physics of Digital Microfabrication. Proc. R. Soc. London, Ser. A 1994, 444, 533. 
(34) Schiaffino, S.; Sonin, A.A. Formation and Stability of Liquid and Molten Beads on a Solid Surface. J. Fluid Mech. 1997, 343, 95.

(35) Pickrell, M. Sun Chemical, Bath, Somerset. Personal communication, 2013.

(36) Stathatos, E.; Kanopoulos, N.; Lianos, P.; Katsagounos, Y.; Makris, T. Scalable Production of Dye-Sensitized Solar Cells using Inkjet Printing. U.S. Patent 2013/0139887 A1 June 6, 2013.

(37) Deegan, R.D.; Bakajin, O.; Dupont, T.F.; Huber, G.; Nagel, S.R.; Witten, T.A. Capillary Flow as the Cause of Ring Stains from Dried Liquid Drops. Nat. 1997, 389, 827.

(38) Young, T. An Essay on the Cohesion of Fluids. Philos. Trans. R. Soc. London 1805, 95, 65.

(39) Stringer, J.; Derby, B. Formation and Stability of Lines Produced by Inkjet Printing. Langmuir 2010, 26, 10365.

(40) Wenzel, R.N. Resistance of Solid Surfaces to Wetting by Water. Ind. Eng. Chem. 1936, 28,988 .

(41) Öhlund, T.; Örtegren, J.; Forsberg, S.; Nilsson, H-E. Paper Surfaces for Metal Nanoparticle Inkjet Printing. Appl. Surf. Sci. 2012, 259, 731.

(42) Lamminmäki, T.; Kettle, J.; Rautkoski, H.; Kokko, A., Gane, P. Limitations of Current Formulations when Decreasing the Coating Layer Thickness of Papers for Inkjet Printing. Ind. Eng. Chem. Res. 2011, 50, 7251.

(43) Svanholm, E. Printability and Ink-Coating Interactions in Inkjet Printing. Ph.D. Dissertation, Karlstad University, Karlstad, Sweden, 2007. 
(44) Ström, G.R.; Borg, J.; Svanholm, E. Short-Time Water Absorption by Model Coatings. In Proceedings TAPPI $10^{\text {th }}$ Advanced Coating Fundamentals Symposium, Montreal, 2009; Paper 5.3.

(45) IPC-TM-650 Test Methods Manual; 2.6.2; IPC, Flexible Circuits Test Methods Subcommittee: Illinois, 2012; pp. 1-2.

(46) Summary of Properties for Kapton ${ }^{\circledR}$ Polyimide Films; Dupont http://www2.dupont.com/Kapton/en_US/assets/downloads/pdf/summaryofprop.pdf (accessed Jun 15, 2013).

(47) Dupont ${ }^{\mathrm{TM}}$ Teflon ${ }^{\circledR}$ PTFE TE-3885 Fluoropolymer Resin; Dupont, 2005 http://www2.dupont.com/Teflon_Industrial/en_US/assets/downloads/k15764.pdf (accessed Jun $15,2013)$.

(48) MatWeb: Online Materials Information Resource. http://www.matweb.com (accessed Jun $15,2013)$.

(49) Van den berg, A.M.J.; De Laat, A.W.M.; Smith, P.J.; Perelaer, J.; Schubert, U.S. Geometric Control of Inkjet Printed Features using a Gelating Polymer. J. Mater. Chem. 2007, 17,677 .

(50) Soltman, D.B. Understanding Inkjet Printed Pattern Generation. Ph.D. Dissertation, University of California at Berkeley, United States, 2011.

(51) Wang, J.Z.; Zheng, Z.H.; Li, H.W.; Huck, W.T.S.; Sirringhaus, H. Dewetting of conducting polymer inkjet droplets on patterned surfaces. Nat. Mater. 2004, 3, 171. 


\section{TABLE CAPTION LIST}

Table 1: Contact Angle Values Measured for Untreated and Surface Modified RO3006 Substrate using Water (triply distilled) and Diiodomethane.

Table 2: Contact Angle Values Measured for Untreated and Surface Modified RO3006 Substrate using Silver Inks.

Table 3: Printing Trials Involving Different Curing Levels and Platen Temperatures.

Table 4: Average Thickness of EMD 6200 Before and After Thermal Curing.

Table 5: Comparison Between Predicted and Measured Line Widths on Surface Modified Substrates.

Table 6: Static and Advancing Contact Angles for Acetone onto EMD 6200 Coating. 
Table 1. Contact Angle Values Measured for Untreated and Surface Modified RO3006 Substrate using water (triply distilled) and Diiodomethane.

$\begin{array}{lccc}\text { Surface Treatment Applied } & \begin{array}{c}\text { Measured Contact } \\ \text { Angle } \\ - \text { Water }\left(^{\mathrm{a}}\right)\end{array} & \begin{array}{c}\text { Measured Contact } \\ \text { Angle } \\ \text { Diiodomethane }^{\mathrm{a}}\left(^{\circ}\right)\end{array} & \begin{array}{c}\text { Measured Surface } \\ \text { Energy }(\mathrm{mN} / \mathrm{m})^{\mathrm{b}}\end{array} \\ \text { Untreated RO3006 } & 118.3 & 90.1 & 14.6 \\ \text { Hydrophobic coating } & 134.1 & 96.6 & 9.9 \\ \text { SU-8 coating } & 86.8 & 55.1 & 31.1 \\ \text { EMD 6200 coating } & 92.9 & 21.0 & 48.0\end{array}$

${ }^{a}$ Averaged contact angle measurements. ${ }^{b}$ Surface energy calculated using the Owens-WendtRabel-Kaelble method. 
Table 2. Contact Angle Values Measured for Untreated and Surface Modified RO3006 Substrate using Silver Inks.

$\begin{array}{lc}\text { Surface Treatment Applied } & \text { Measured Contact Angle }\left({ }^{\circ}\right)^{\mathrm{c}} \\ \text { Untreated RO3006 }^{\mathrm{d}} & 47 \\ \text { Hydrophobic coating }^{\mathrm{d}} & 76 \\ \text { SU-8 coating }^{\mathrm{d}} & 41 \\ {\text { EMD } 6200 \text { coating }^{\mathrm{e}}}^{\text {EN }} & 50\end{array}$

${ }^{\mathrm{c}}$ Averaged contact angle measurements. ${ }^{\mathrm{d}}$ Using DGP 40LT-15C ink (Advanced Nano Products). ${ }^{\mathrm{e}}$ Using EMD 5603 ink (Sun Chemical). 
Table 3. Printing Trials Involving Different Curing Levels and Platen Temperatures.

\begin{tabular}{ccccc} 
Trial No. $^{\mathrm{f}}$ & No. of coat $(\mathrm{s})^{\mathrm{g}}$ & UV cure level ${ }^{\mathrm{h}}$ & $\begin{array}{c}\text { Platen Temperature } \\
\left({ }^{\circ} \mathrm{C}\right)\end{array}$ & Curing Condition \\
\hline 1 & 1 & 1 & 25 & In-line \\
2 & 1 & 1 & 60 & In-line \\
3 & 1 & 2 & 60 & In-line \\
4 & 1 & 3 & 60 & In-line \\
5 & 2 & 2 & 60 & In-line \\
6 & 2 & 1 & 60 & In-line \& Off-line ${ }^{\mathrm{i}}$ \\
7 & 2 & 1 & 60 & In-line
\end{tabular}

${ }^{\mathrm{f}}$ The printed area coverage is around $4 \times 1 \mathrm{~cm}$ in each trial. ${ }^{\mathrm{g}}$ Colorless coating observed after curing. ${ }^{h}$ The corresponding cure intensities are provided in Section 3.3. ${ }^{\mathrm{i}}$ For the off-line curing, 3 rounds of raster curing was used. 
Table 4. Average Thickness of EMD 6200 Before and After Thermal Curing.

$\begin{array}{ccc}\begin{array}{c}\text { Platen Temperature } \\ \left({ }^{\circ} \mathrm{C}\right)\end{array} & \begin{array}{c}\text { Cure Level } \\ 40\end{array} & \begin{array}{c}\text { Average Thickness } \\ (\mu \mathrm{m})\end{array} \\ 40 & 1,1 & 20.3^{\mathrm{j}} \\ 40 & 1,1 & 10.4^{\mathrm{k}} \\ 40 & 1,2 & 23.6^{\mathrm{j}} \\ 30 & 1,2 & 18.0^{\mathrm{k}} \\ 30 & 1,2 & 25.3^{\mathrm{j}} \\ & 1,2 & 13.0^{\mathrm{k}}\end{array}$

${ }^{\mathrm{j}}$ Before thermal curing. ${ }^{\mathrm{k}}$ After thermal curing. 
Table 5. Comparison Between Predicted and Measured Line Widths on Surface Modified Substrates.

\begin{tabular}{|c|c|c|c|c|c|}
\hline \multirow{2}{*}{$\begin{array}{l}\text { Surface } \\
\text { Modification }\end{array}$} & \multirow[b]{2}{*}{$\mathrm{R}_{\mathrm{a}}(\mu \mathrm{m})$} & \multirow{2}{*}{$\begin{array}{c}\text { Measured } \\
\text { Contact } \\
\text { Angle }\left(^{\circ}\right)^{1}\end{array}$} & \multicolumn{3}{|c|}{ Line Width $(\mu \mathrm{m})$} \\
\hline & & & $\begin{array}{c}\text { Smith et al. } \\
\text { [1] }\end{array}$ & $\begin{array}{c}\text { Eqn. (4) with } \\
k=1.2\end{array}$ & Measured \\
\hline Untreated & 0.76 & 47 & 57.7 & 83.3 & 88.2 \\
\hline $\begin{array}{l}\text { Abrasive sheet } \\
\text { (P1200) }\end{array}$ & 0.80 & 67 & 46.0 & 57.8 & 54.1 \\
\hline $\begin{array}{l}\text { Hydrophobic } \\
\text { coating }\end{array}$ & 0.93 & 76 & 41.5 & 50.9 & 48.2 \\
\hline
\end{tabular}

${ }^{1}$ Averaged contact angle measurements. 
Table 6. Static and Advancing Contact Angles for Acetone onto EMD 6200 Coating.

$\begin{array}{ccc}\text { Measurement } & \text { Static Contact Angle }\left(^{\circ}\right) & \text { Advancing Contact Angle }\left({ }^{\circ}\right)^{\mathrm{m}} \\ 1 & 26.4 & 30.1 \\ 2 & 30.5 & 28.7 \\ 3 & 26.7 & 23.3 \\ 4 & 27.3 & 27.0 \\ 5 & 31.2 & 32.6 \\ 6 & 30.4 & 32.0 \\ \mathrm{~m}_{3} \text { drops dispensed/measurement for obtaining the advancing contact angles. }\end{array}$




\section{FIGURE CAPTION LIST}

Figure 1: SEM image of the untreated surface of RO3006 substrate.

Figure 2: Cross-section of the surface modified RO3006, with the planarization layer.

Figure 3: Spin-coated SU-8 onto RO3006 substrate (A) After the first coat. (B) After the second coat.

Figure 4: Surface morphology characterization process.

Figure 5: (A) Ink de-wetting phenomenon in Trial 1. (B) Improved wetting in Trial 2. (C) Trial 3 (D) Trial 4.

Figure 6: (A) Trial 6 - First coat after off-line curing. (B) Trial 6 - Second coat after off-line curing. (C) Trial 7 - First coat. (D) Trial 7 - Second coat.

Figure 7: Effects of platen temperature and UV cure levels on the cured EMD 6200 thickness.

Figure 8: Coated EMD 6200 with platen temperature set at $30^{\circ} \mathrm{C}$, cure levels 1,1. (A) After first coat. (B) After the second coat.

Figure 9: Error bar plots for the average surface roughness $\left(\mathrm{R}_{\mathrm{a}}\right)$ for the different types of surface modifications.

Figure 10: (A) Top view of metal trace printed on corona-treated SU-8 coated substrate. (B) Trace outlines observed under optical 3D imaging (InfiniteFocus, Alicona Imaging GmbH).

Figure 11: Diagram showing relationship between surface roughness and printed line width. 
Figure 12: Test lines printed on (A) Untreated RO3006. (B) Hydrophobic-coated RO3006. (C) SU-8 coated RO3006. (D) EMD 6200 coated RO3006.

Figure 13: (A) Top view of SU-8 layer. (B) Cross-section view of SU-8 layer.

Figure 14: Top view of EMD 6200 coat.

Figure 15: Correlation of measured static contact angle against predicted line with, with and without factor $\mathrm{k}$.

Figure 16: Printed drops on (A) EMD 6200 coating. (B) Untreated RO3006 substrate.

Figure 17: Top view showing initial and final outline of printed trace on EMD 6200 coat. 


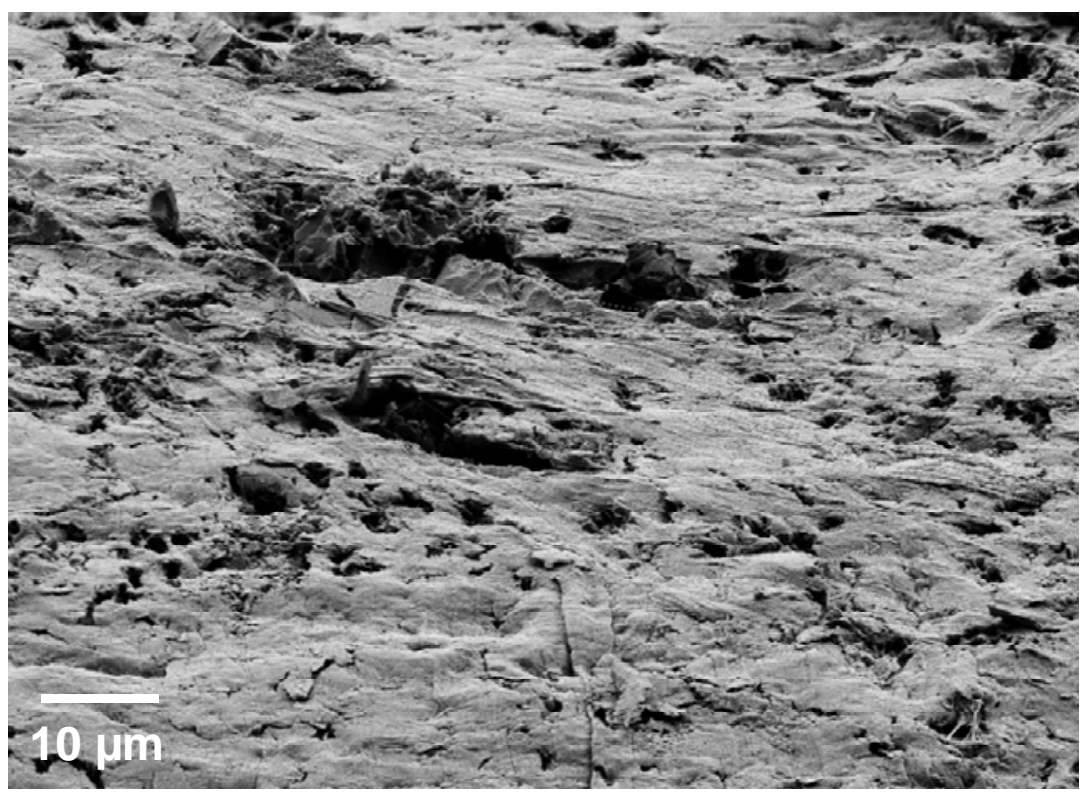

Figure 1. SEM image of the untreated surface of RO3006 substrate. 


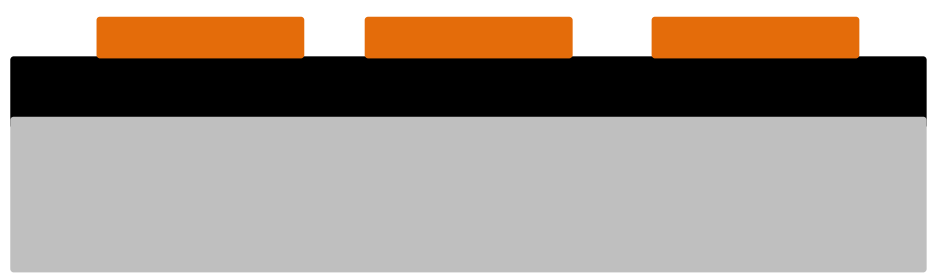

R03006 substrate

Planarization layer (SU-8)

Metal traces

Figure 2. Cross-section of the surface modified RO3006, with the planarization layer. 


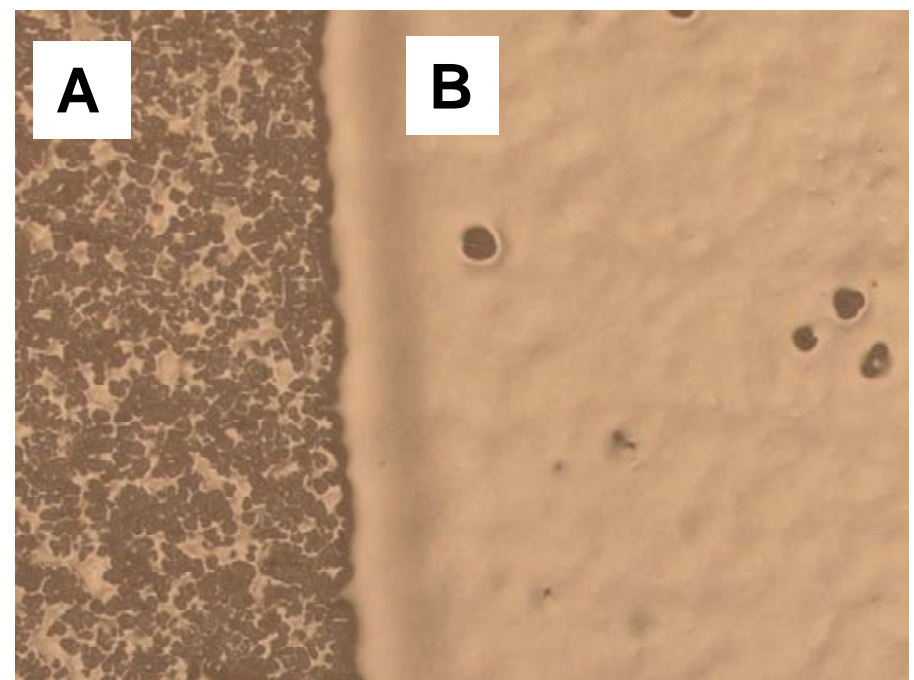

Figure 3. Spin-coated SU-8 onto RO3006 substrate (A) After the first coat. (B) After the second coat. 


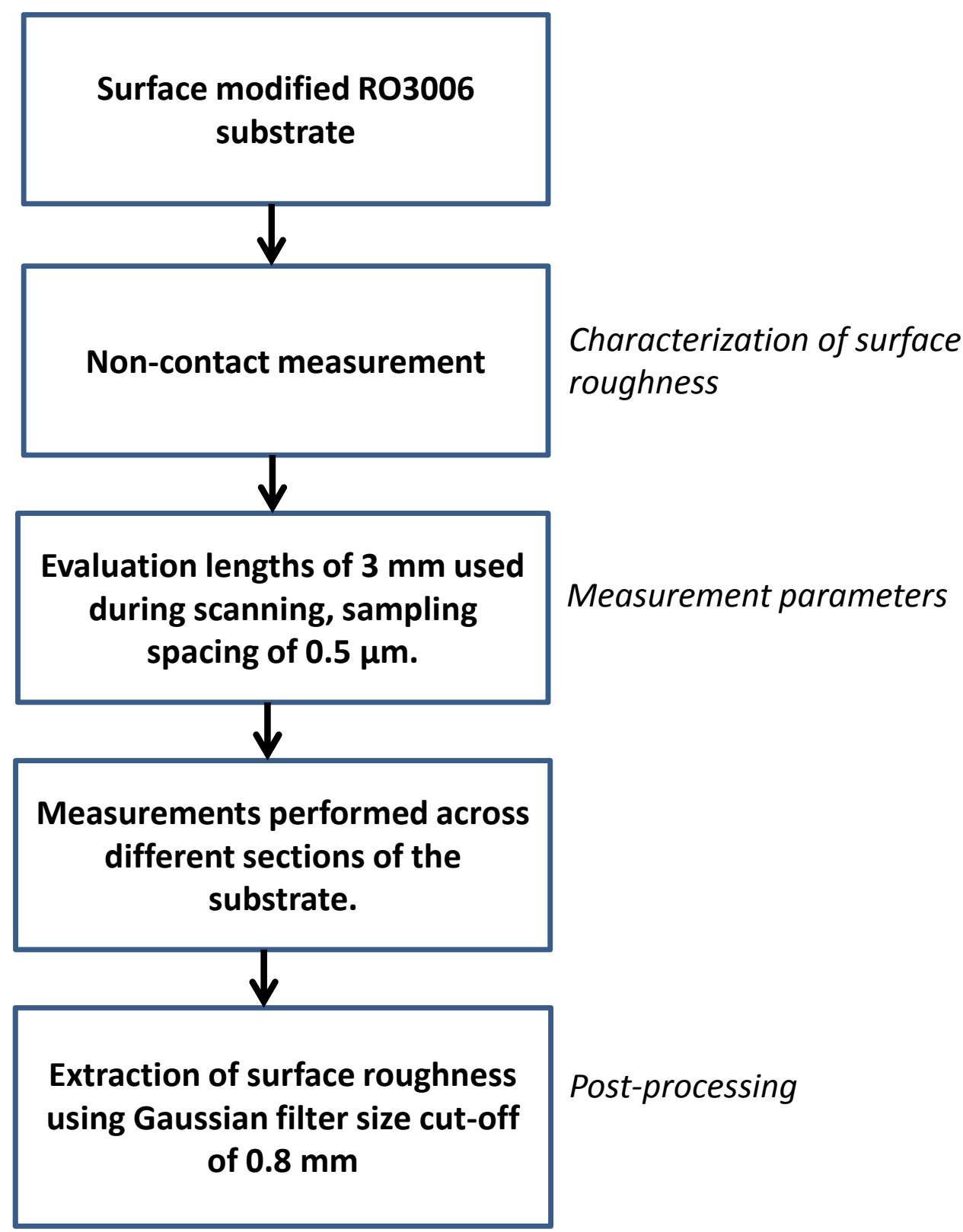

Figure 4. Surface morphology characterization process 

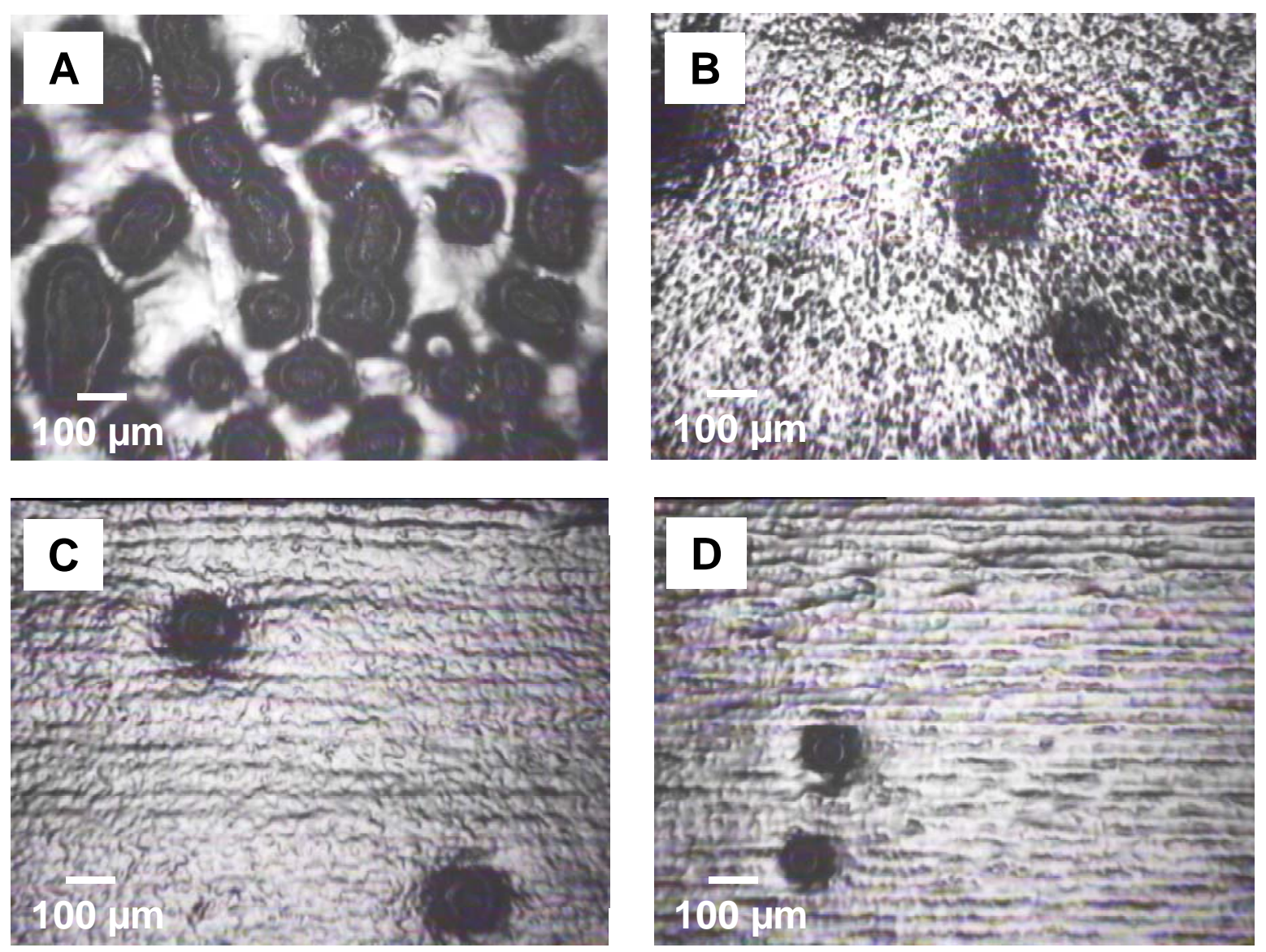

Figure 5 (A) Ink de-wetting phenomenon in Trial 1. (B) Improved wetting in Trial 2. (C) Trial 3

(D) Trial 4. Colorless coats were observed after curing. 

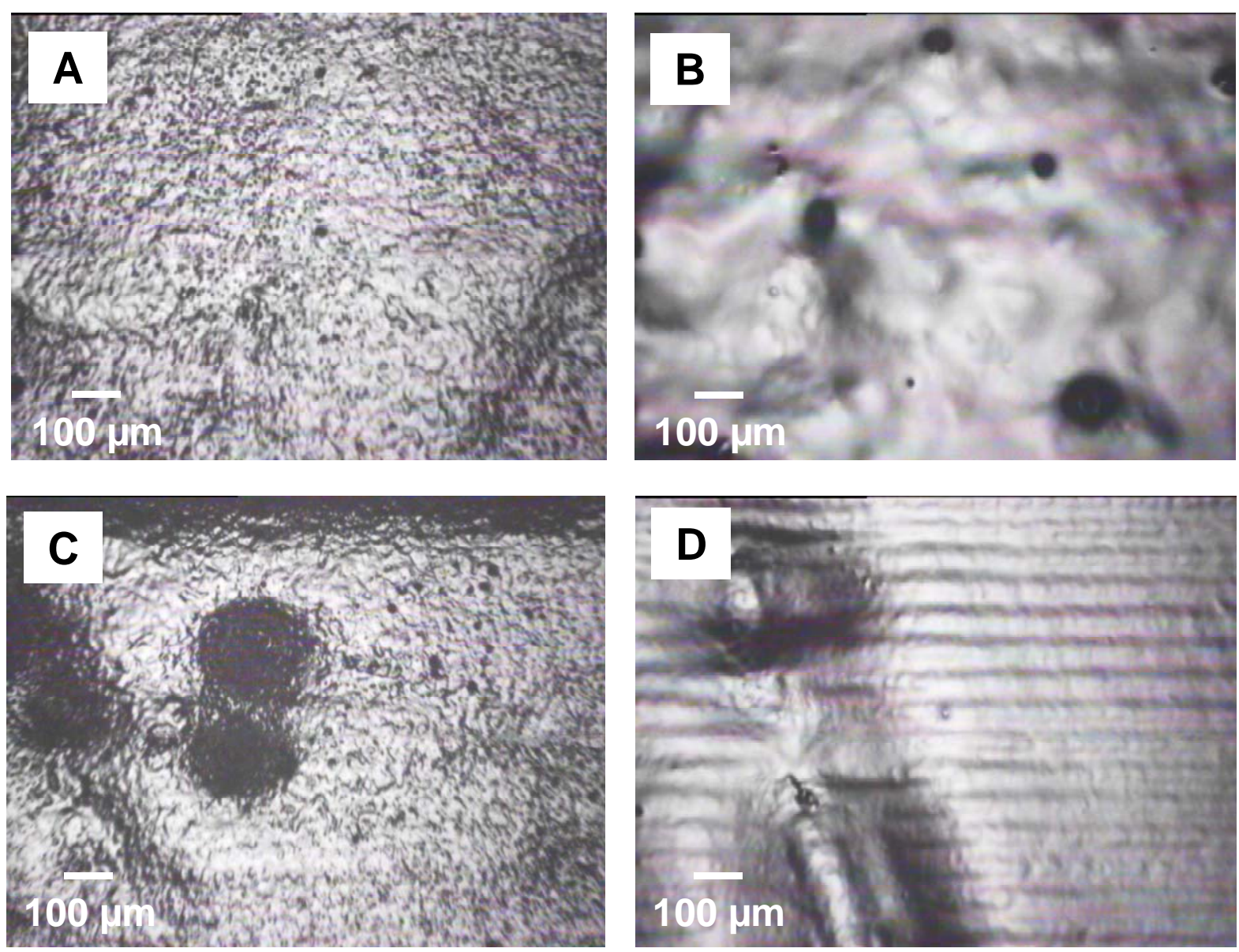

Figure 6. (A) Trial 6 - First coat after off-line curing. (B) Trial 6 - Second coat after off-line curing. (C) Trial 7 - First coat. (D) Trial 7 - Second coat. Colorless coats were observed after curing. 


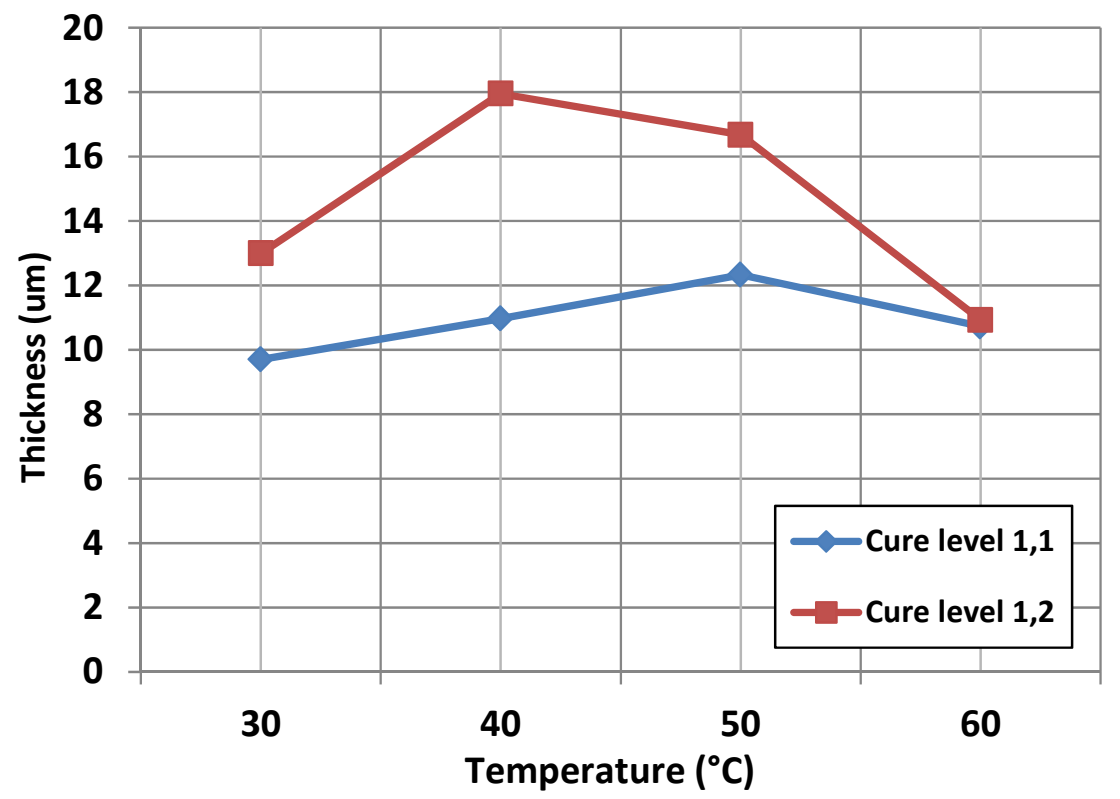

Figure 7. Effects of platen temperature and UV cure levels on the cured EMD 6200 thickness. 

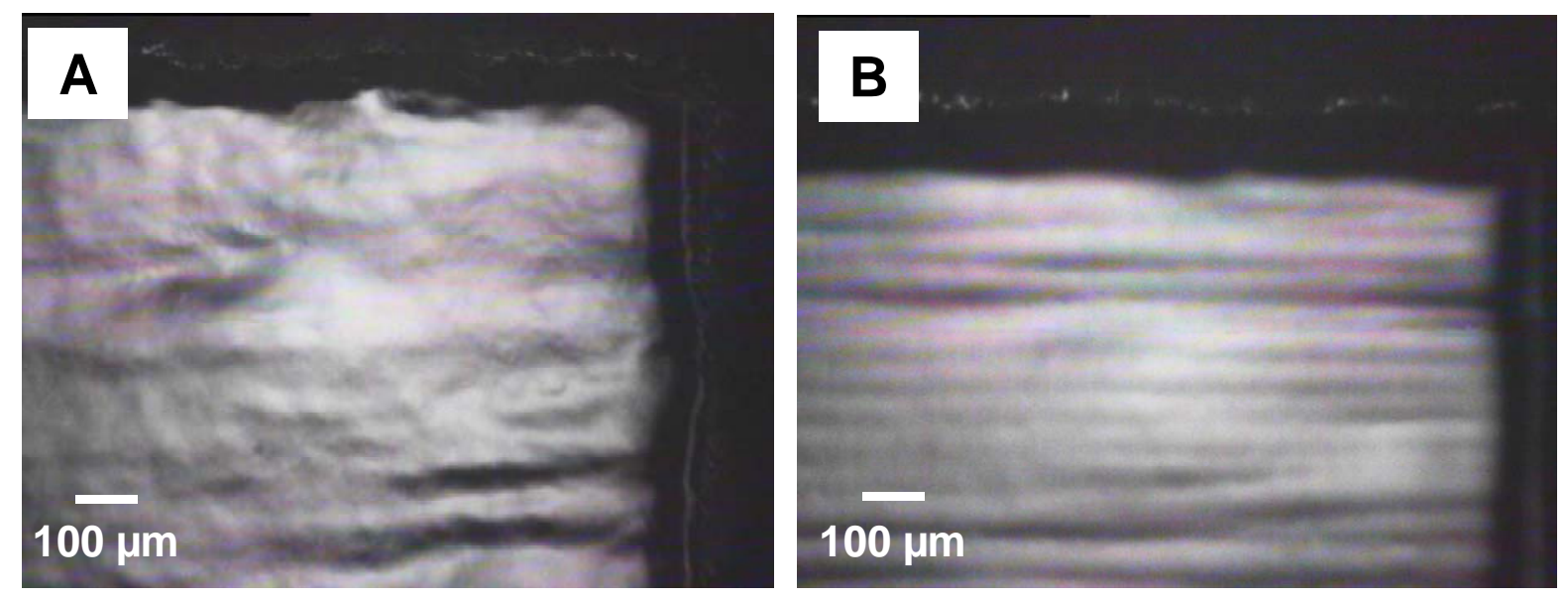

Figure 8. Coated EMD 6200 with platen temperature set at $30^{\circ} \mathrm{C}$, cure levels 1,1. (A) After first coat. (B) After the second coat. 


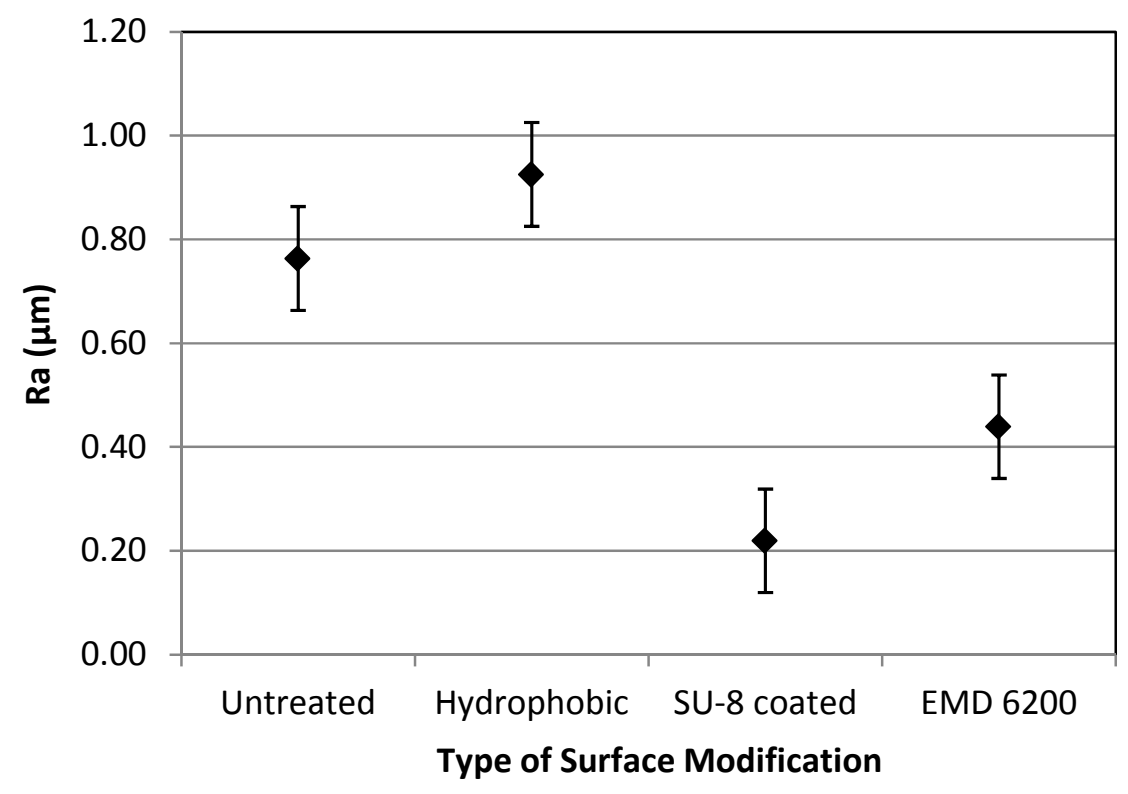

Figure 9. Error bar plots for the average surface roughness $(\mathrm{Ra})$ for the different types of surface modifications. 

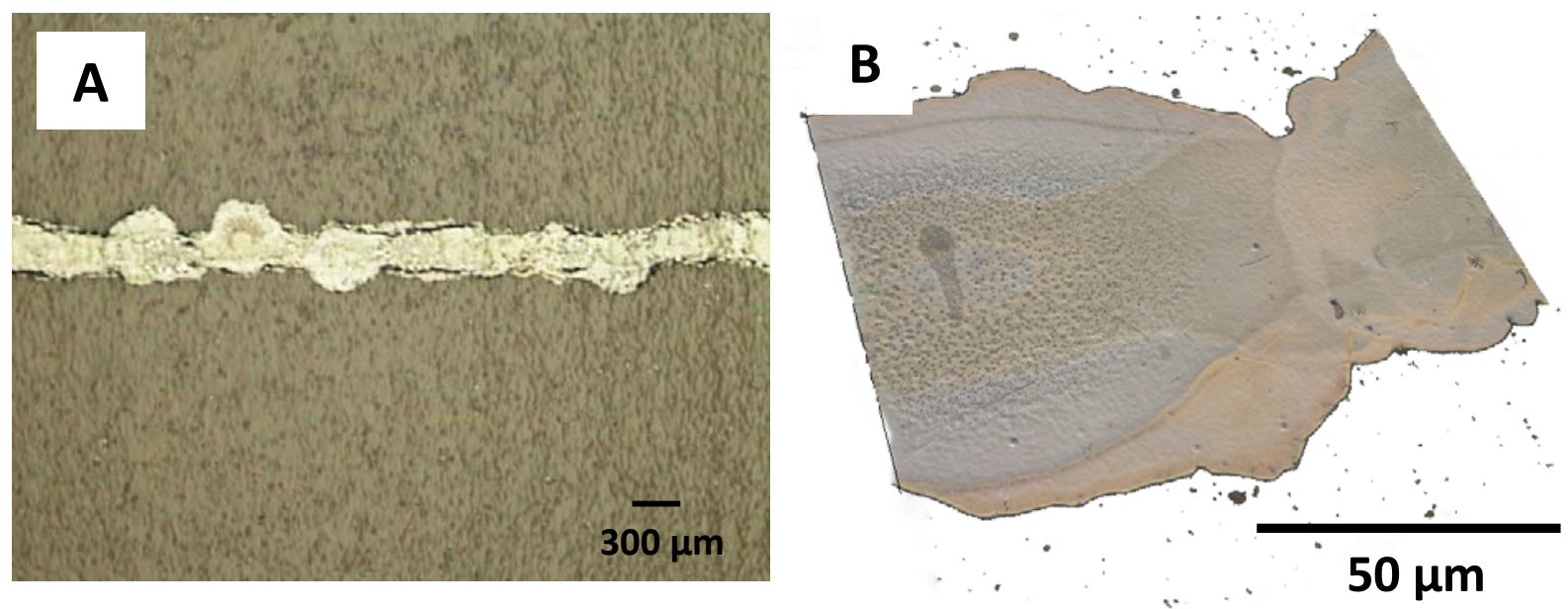

Figure 10. (A) Top view of metal trace printed on corona-treated SU-8 coated substrate. (B) Trace outlines observed under optical 3D imaging (InfiniteFocus, Alicona Imaging GmbH). 


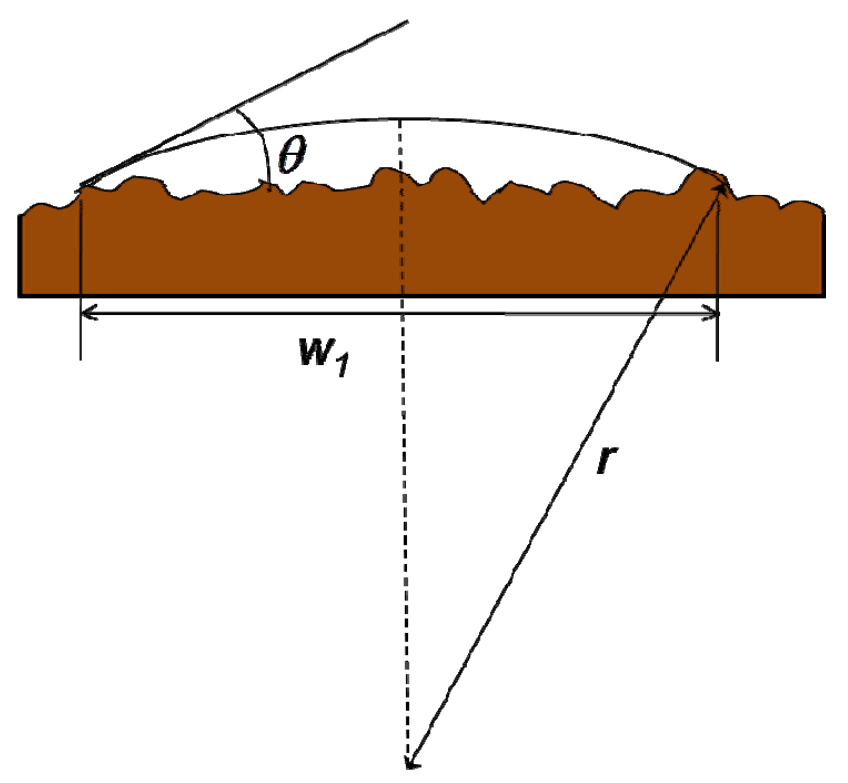

Figure 11. Diagram showing relationship between surface roughness and printed line width. 

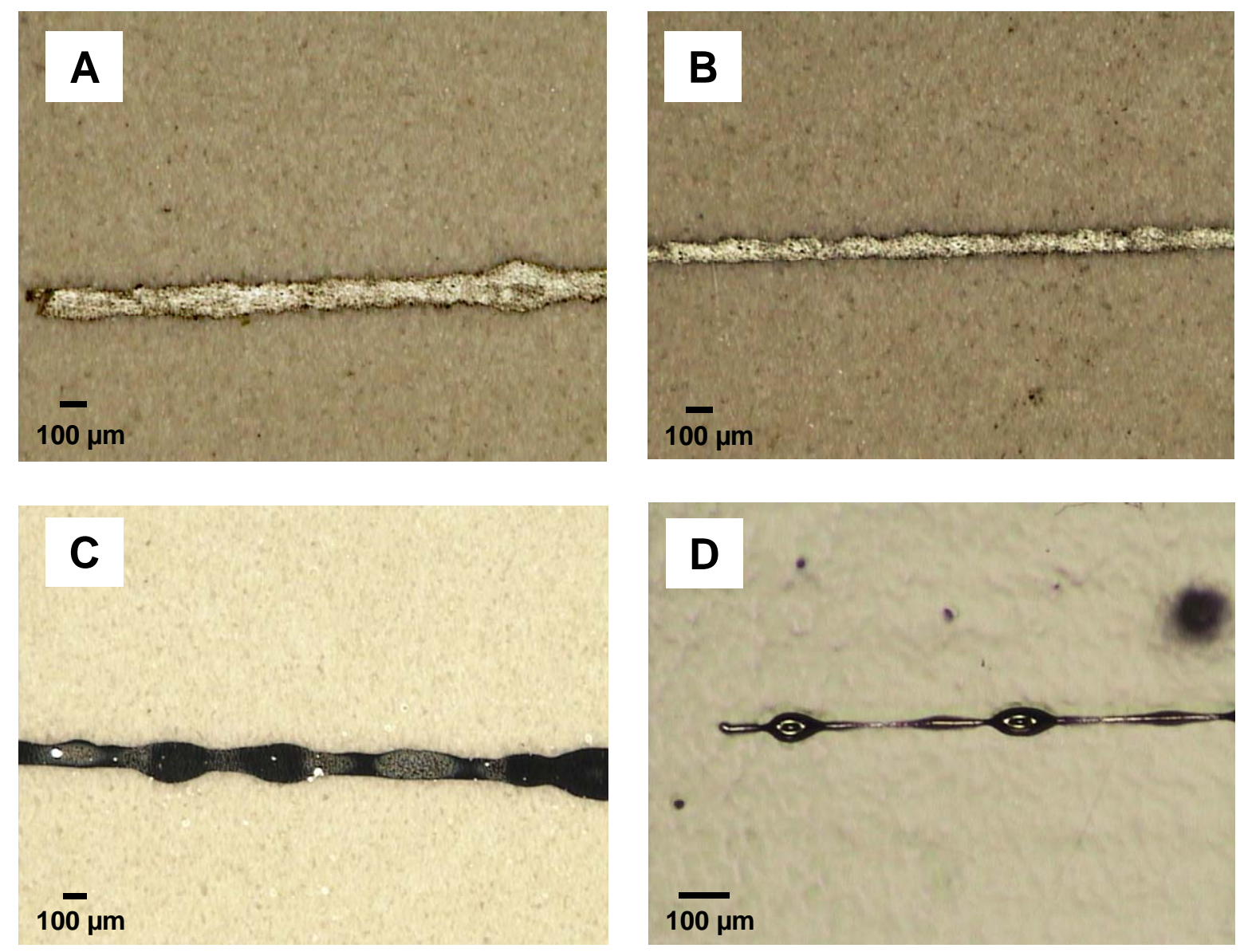

Figure 12. Test lines printed on (A) Untreated RO3006. (B) Hydrophobic-coated RO3006. (C) SU-8 coated RO3006. (D) EMD 6200 coated RO3006. 

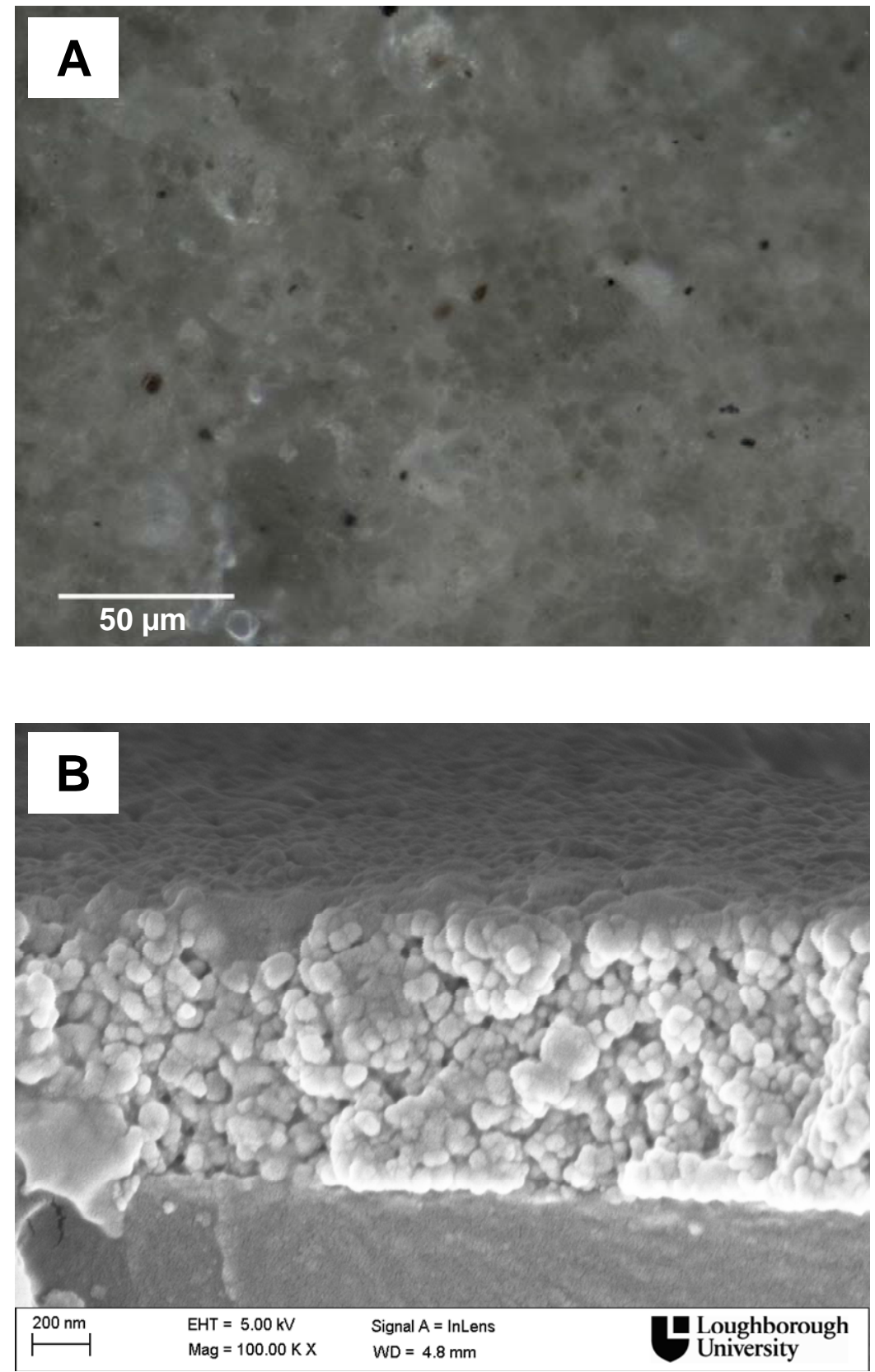

Figure 13. (A) Top view of SU-8 layer. (B) Cross-section view of SU-8 layer. 


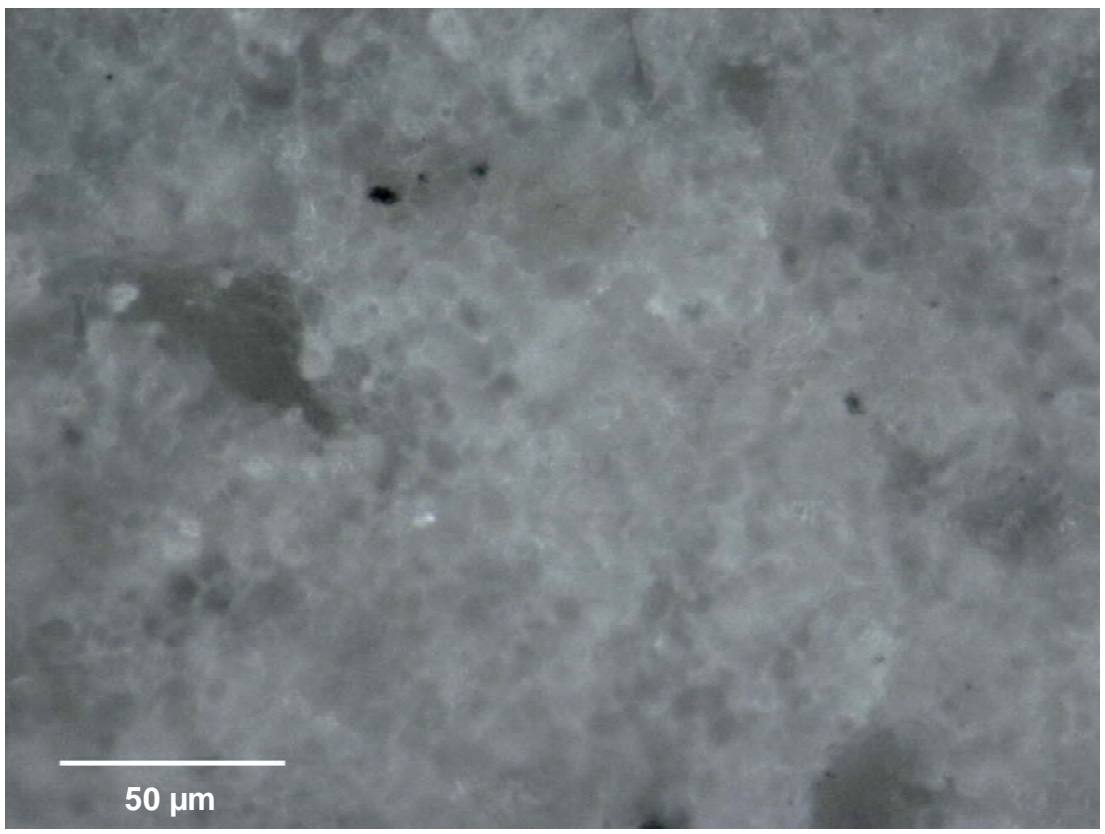

Figure 14. Top view of EMD 6200 coat. 


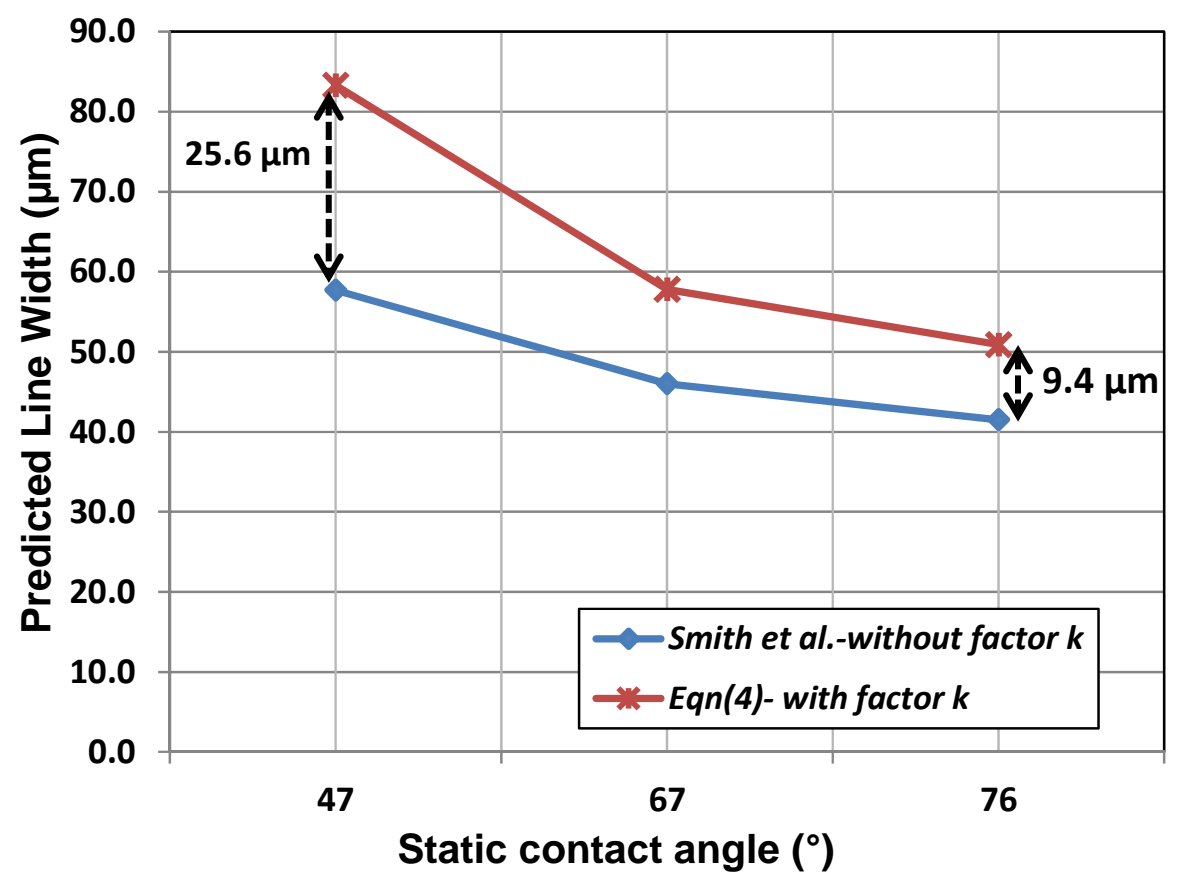

Figure 15. Correlation of measured static contact angle against predicted line width, with and without factor $\mathrm{k}$. 


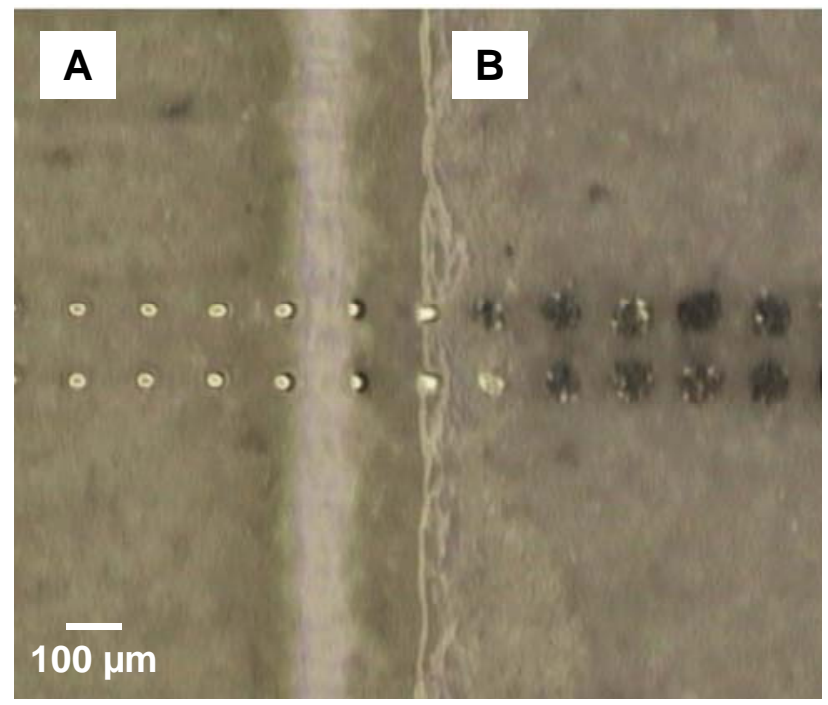

Figure 16. Printed drops on (A) EMD 6200 coating. (B) Untreated RO3006 substrate. 


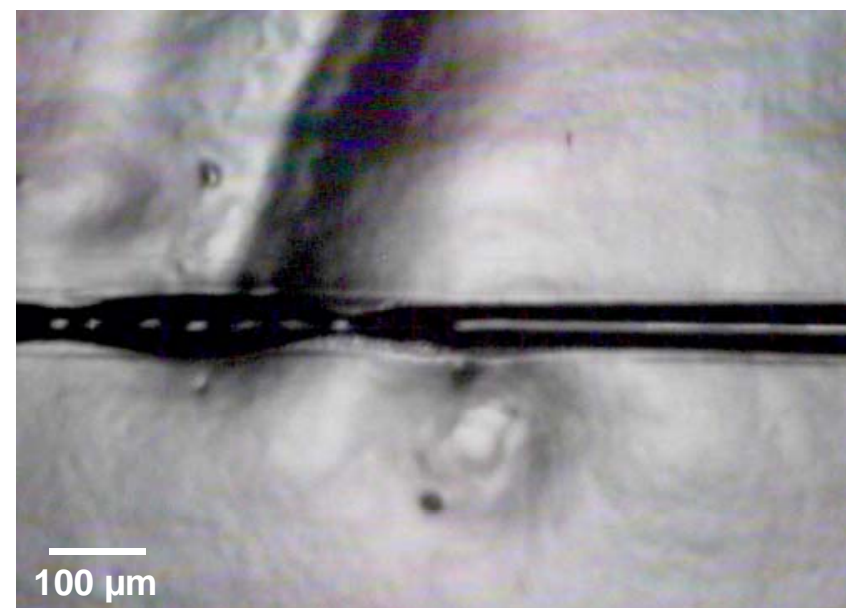

Figure 17. Top view showing the initial and final outline of a printed trace on EMD 6200 coat. 


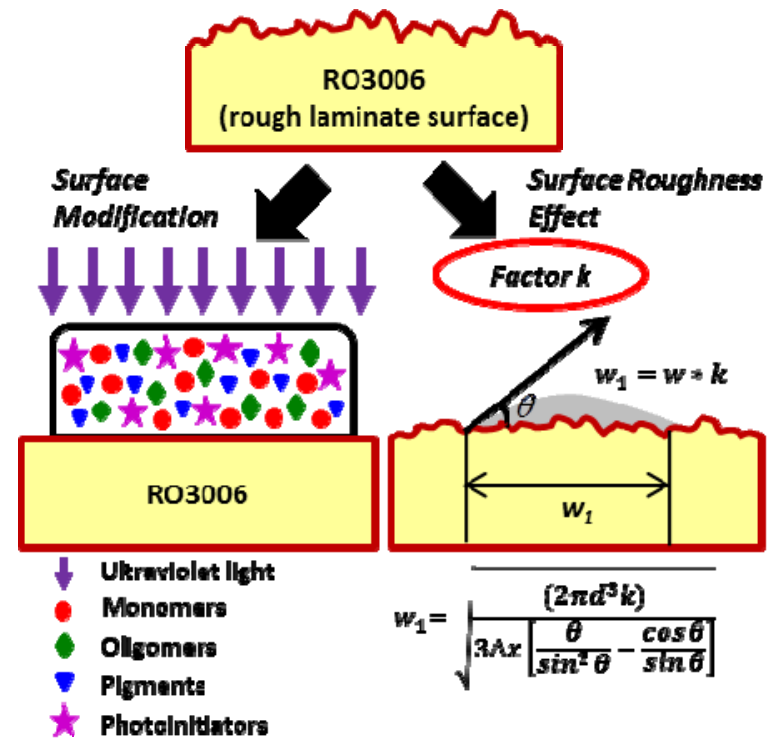

For Table of Contents Only 